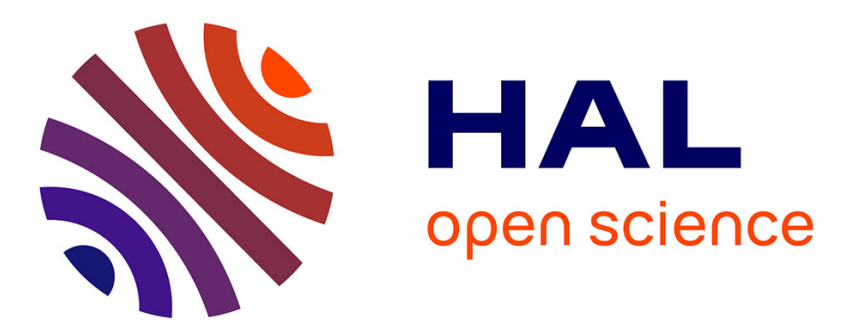

\title{
Cure or sell : how do pharmaceutical industry marketers combine their dual mission? An approach using moral dissonance
}

Bénédicte Bourcier-Bequaert, Loréa Baïada-Hirèche, Anne Sachet-Milliat

\section{- To cite this version:}

Bénédicte Bourcier-Bequaert, Loréa Baïada-Hirèche, Anne Sachet-Milliat. Cure or sell : how do pharmaceutical industry marketers combine their dual mission? An approach using moral dissonance. Journal of Business Ethics, 2022, 175 (3), pp.555-581. 10.1007/s10551-020-04657-4 . hal-03023906

\section{HAL Id: hal-03023906 https://hal.science/hal-03023906}

Submitted on 26 Nov 2020

HAL is a multi-disciplinary open access archive for the deposit and dissemination of scientific research documents, whether they are published or not. The documents may come from teaching and research institutions in France or abroad, or from public or private research centers.
L'archive ouverte pluridisciplinaire HAL, est destinée au dépôt et à la diffusion de documents scientifiques de niveau recherche, publiés ou non, émanant des établissements d'enseignement et de recherche français ou étrangers, des laboratoires publics ou privés. 


\title{
Cure or sell: how do pharmaceutical industry marketers combine their dual mission? An approach using moral dissonance
}

\author{
Bénédicte Bourcier-Béquaert* \\ ESSCA School of Management, Aix-en-Provence, France \\ benedicte.bourcier-bequaert@essca.fr \\ Loréa Baïada-Hirèche \\ Université Paris-Saclay, Univ Evry, IMT-BS, LITEM, 91025 Evry-Courcouronnes, France \\ lorea.baiada-hireche@imt-bs.eu \\ Anne Sachet-Milliat \\ Groupe ISC Paris, 75017 Paris, France \\ Membre associé du GRANEM, Université d'Angers \\ asachet.milliat@iscparis.com
}

Coming Soon. Published online in Journal of Business Ethics, 2020-10-30

\begin{abstract}
Pharmaceutical industry marketers are confronted with specific ethical issues linked to the tension between the economic interest being pursued and the health mission of this sector. Indeed this dual mission could be problematic for them when the two objectives contradict each other. We use the concept of moral dissonance to examine how marketers in the pharmaceutical industry perceive the profit/health tension inherent in their sector and how they deal with it. Based on narratives of 18 marketers working in the pharmaceutical sector, our qualitative study identifies ethical conflicts of varying intensity that generate differing degrees of moral dissonance among marketers. To cope with this moral dissonance, they use the following strategies: (1) minimize the sensitivity of their activity; (2) invoke the benefits to patients; and (3) avoid behaviors that conflict with their values.
\end{abstract}

\section{Key words}

Marketing practitioner, ethical conflict, pharmaceutical industry, moral dissonance, ways of reducing dissonance, self-justifications, neutralizations, narratives.

*Corresponding author details: Bénédicte Bourcier-Béquaert, Associate Professor in Marketing ESSCA School of Management, 350 avenue du Club Hippique, 13090 Aix-en-Provence.

Tel +33442544005/Mob +33611 403199 


\section{Introduction}

The pharmaceutical industry has been shrouded in controversy because of the various scandals associated with it in recent years. For example, the opioid crisis in the US that is estimated to have caused more than 200,000 deaths because of overdosing ${ }^{1}$. These ethical issues generally arise from the tension between the profit and health missions to which these organizations are committed (Ravelli 2015; Valverde 2012). Pharmaceutical companies are often considered to have a special moral obligation to society because they can improve health and save lives (Huebner 2014; Maitland 2002; Nussbaum 2009), even as they pursue their profit objectives.

Many of the ethical issues raised in this industry relate to marketing activities: drug prices (Valverde 2012), direct-to-consumer advertising (Van de Pol and De Bakker 2010), and the relationships between medical representatives and physicians (Cohn et al. 2014; Katamba et al. 2016; Sah and Fugh-Berman 2013; Shaw and Whitney 2016). However, these issues are mainly examined at the industry level, while ignoring the viewpoint of individuals. Little is known about how marketers live and manage, at their level, the ethical conflicts they may face in their jobs, which are due to the twofold mission of their organizations. However, among employees in this sector, marketers, and salespeople are particularly exposed to ethical tensions because of their job responsibilities. On the one hand, they are in charge of promoting products, and directly linked to economic performance objectives. On the other hand, they have to take into account, in close association with physicians, patient needs and expectations; they are, therefore, at the heart of the health mission.

This double constraint might be problematic if there is a contradiction between the two objectives. Consequently, it seems important to question the consequences of such a context on marketers working in the pharmaceutical industry. This issue is all the more significant because research 
suggests a mismatch between the values of employees (e.g., prioritizing benefits for patients) and those of their work environment (e.g., seeking profit above all else) affects them adversely (KristofBrown et al. 2005). In particular, value incongruence has been shown to lead to a loss of work commitment and an increase in turnover intention (Kristof-Brown et al. 2005). Moreover, it negatively affects psychological health and even causes burn-out (Bao et al. 2013; Doblhofer et al. 2019; Siegall and McDonald 2004). However, the way employees cope with this stressful situation has rarely been explored (Doblhofer et al. 2019). The purpose of this study is, therefore, to address this issue. How do marketers in the pharmaceutical industry perceive the tension inherent in their sector? How do they deal with it?

In order to examine these questions, we use the concept of moral dissonance (Kelman and Baron 1974; Holland et al. 2002; Lowell 2011). Moral dissonance occurs when an individual's behavior or his or her cognitions are in conflict with his or her moral values. This is the case when marketers in the pharmaceutical industry are confronted with situations where there is a conflict between profit and health objectives. Because these situations may be detrimental to patients' health or wellbeing, they may conflict with the moral values of marketers, thereby giving rise to a state of moral dissonance. Since moral dissonance creates strong psychological discomfort, individuals tend to reduce it by using several modes; the most common one is to justify themselves (Holland 2002; Lowell 2011).

In this research, we, therefore, asked ourselves: to what extent do marketers experience situations of moral dissonance that are linked to the profit/health tension inherent in the pharmaceutical industry? And what types of strategies do they use to cope with it?

We conducted 18 semi-directive interviews with marketing decision makers working in the pharmaceutical sector in France by asking them about the ethical issues encountered in the context of their activity. Our qualitative study identifies ethical conflicts of varying intensity, linked to their 
dual profit and health mission, that generate differing degrees of moral dissonance among marketers. To cope with this moral dissonance, they use the following strategies: (1) minimize the sensitivity of their activity; (2) invoke the patient benefit; and (3) avoid behaviors that conflict with their values.

Our study shows that the concept of moral dissonance sheds interesting light on a central problem in behavioral ethics: how individuals deal with a work environment which repeatedly challenges their ethical values, even as they remain true to their values. This is the case of marketers in the pharmaceutical industry who face a double constraint because of the structural tension characterizing their activity. Based on a rich qualitative study conducted with professionals, our research details the concrete ethical conflicts they experience, thereby generating moral dissonance, and the various strategies they deploy to deal with it in accordance with the moral intensity of the conflicts. Thus our results capture the processes spontaneously adopted for reducing moral dissonance in real organizational settings. They also reveal the variety and subtlety of the modes of dissonance reduction used by marketers in close connection with their health mission.

The first part presents the ethical issues in the pharmaceutical industry, as well as the theoretical framework: moral dissonance and the strategies put in place to reduce it, including neutralization techniques. Then, the qualitative methodology is presented; it explains how the sensitivity of the topic was taken into account in the collection and analysis of data. The results detail the ethical conflicts experienced by the respondents and strategies adopted. These are then discussed and the practical implications identified.

\section{Ethical conflicts and marketers' moral dissonance in the pharmaceutical}

\section{industry}


Ethical issues in marketing in the pharmaceutical industry

Owing to the very nature of its products, which aim to improve people's health and even save lives, the pharmaceutical industry is considered by many specialists to have a particular moral obligation to society (Huebner 2014; Nussbaum 2009). This moral mission is accentuated by the need to protect patients who are in a vulnerable situation due to the asymmetry in information with respect to experts (Crié and Chebat 2013). Therefore, societal expectations are very high in terms of equal access to medicine and transparency. These are reflected in the strict regulations that govern the pharmaceutical industry, extending from innovation to the operationalization of marketing mix variables, such as product, price, distribution, and promotion, particularly in France (Stremersch and Van Dyck 2009). However, despite the increasingly strict regulations being implemented, as well as the professional deontology to which health practitioners (e.g., physicians and pharmacists) are subject, the health industry is among those with the most controversial record (Nussbaum 2009). Beyond the multiple health scandals that afflict this sector, the usual working of the system can also be seen as problematic (Ravelli 2015).

Marketing in the pharmaceutical industry throws up particular challenges related to the specific characteristics of this sector. The ethical issues raised are mainly concerned with price, product, and promotion policies (Crié and Chebat 2013). The price of healthcare offers determines their accessibility for patients (Valverde 2012) and has a significant impact on public health financing (Cohn 2016). Product quality and safety are central to consumers/patients. Unfortunately, it has been pointed out that the marketing by pharmaceutical laboratories lacks transparency about the effects of substances, including the risks of side effects, in dealings with the health authorities for obtaining marketing authorization to launch a new medicine (Steffen et al. 2018), as well as with doctors and patients (Ravelli 2015). 
In countries that allow it, direct-to-consumer advertising appears to be a highly controversial practice, with high stakes in terms of consumer safety and autonomy (Van de Pol and De Bakker 2010). Even as these practices are increasingly being regulated, one witnesses regular denouncements of promotional actions targeting health professionals, doctors, and pharmacists (medical visitors, gift offers, invitations to conferences, financing of continuous medical education, etc.) (Ravelli 2015; Sah and Fugh-Berman 2013).

In general, the common thread binding the various ethical issues raised by health marketing is their direct or indirect link to the permanent tension between profit and health to which these organizations are subjected (Ravelli 2015; Valverde 2012).

\section{Ethical conflicts experienced by marketers in the pharmaceutical industry}

The pharmaceutical industry's marketers are potentially in the grip of ethical conflicts generated by the tension between economic logic and health. Based on the work of Rokeach (1968), Kammeyer-Mueller et al. (2012, p.3) define ethical conflict as "a subjective sense that expectations for one's behavior are inconsistent with one's belief regarding what is right or wrong." An ethical conflict principally arises when one must choose between two competing principles governing behavior.

This tension can be found at different levels (Dion 2012). At the sectoral and organizational level, there may be a gap between societal expectations regarding public health and the potentially deviant behavior of companies in this industry. At the individual level, there may be a conflict between the personal values of employees working for these firms and the more or less ethical 
organizational expectations of their employer (e.g., lack of transparency regarding the potentially detrimental effects of their products) (Kammeyer-Mueller et al. 2012; Umphress and Bingham 2011).

Research that has focused on the ethics of health marketing mainly has a sectoral-level focus. Apart from a rare few studies by sociologists on the daily work of medicine workers, most of the research studies do not cover health sector organizations (Fournier et al. 2014; Ravelli 2015). They, therefore, do not allow these questions to be addressed in terms of the concrete ethical issues that marketers face in their practice. However, these situations may be very problematic for the employees experiencing them, as well as their companies. Numerous studies have clearly pointed out the need for congruence between the values of individuals and those of their organization (Amos and Weathington 2008; Edwards and Cable 2009; Kristof-Brown et al. 2005).

When an employee's values do not match those of his or her organization, resulting in the so-called value incongruence, job dissatisfaction, loss of work commitment, and increased turnover intention may follow (Kristof-Brown et al. 2005). This mismatch also negatively affects employee psychological and physiological health and can even lead to emotional exhaustion and burn-out (Bao et al. 2013; Doblhofer et al. 2019; Siegall and McDonald 2004; Tong et al. 2015). Although extant research supports that value incongruence results in psychological strain, the way employees cope with this stressful work situation has received little attention (Doblhofer et al. 2019).

In line with several authors (Bazerman and Banaji 2004; Konovsky and Jaster 1989; Lowell 2011; Messick and Tenbrunsel 1996; Sims 1992), we believe that turning to social psychology might be very helpful to address the ethical issues involved. In particular, the concept of moral dissonance 
can shed a new light on this psychological discomfort, as well as the different coping strategies adopted by individuals.

\section{Moral dissonance and neutralization strategies}

Although it has existed for some time, the concept of moral dissonance has been little explored to date. Initially proposed by the psycho-sociologists Kelman and Baron (1974) in the context of an experimental study, and then taken up by Holland et al. (2002) also in a social psychology experiment, it has been more recently mobilized in the field of business ethics by Lowell (2011) in a conceptual research. Several studies, without explicitly referring to the concept of moral dissonance, examine the same type of phenomenon by looking at the dissonance that emerges when unethical behaviour is adopted (Ashforth and Anand 2003; Humphress and Bingham 2011; Travis and Aronson 2015, Tsang 2002). This work can therefore be drawn up to enrich our analysis of moral dissonance.

\section{Concept of moral dissonance}

Moral dissonance is defined as a particular form of cognitive dissonance that incorporates a moral dimension. This occurs when an individual's behavior or cognitions are in conflict with his or her moral values. Moreover, the supposedly immoral act may have negative consequences for others (Holland et al. 2002a; Kelman and Baron 1974; Lowell 2011). This type of dissonance contrasts with hedonistic dissonance, that arises when a person's actions result in harmful consequences for himself or herself (Kelman and Baron 1974; Holland et al. 2002). 
Moral dissonance may ensue in the event of both minor and serious unethical acts (Tsang 2002).

The deviance involved may be committed on behalf of the organization or concern routine management decisions (Ashforth and Anand 2003; Lowell 2011; Umphress and Bingham 2011). Indeed, a questionable decision or even an error of judgment may trigger a process of moral dissonance. Several factors increase the arousal of dissonance: when individuals feel responsible for predictable and irreversible negative consequences, or when they are irrevocably engaged in a situation and have invested a lot (time, money, effort) in the act that brings about the harmful consequences (Cooper and Fazio 1984; Holland et al. 2002; Lowell 2011; Sears et al. 1991). Furthermore, the level of moral dissonance is also influenced by the potential seriousness of an unethical act (Umphress and Bingham 2011). This finding is consistent with previous theoretical research on the intensity of moral issues (Jones 1991). Umphress and Bingham (2011) give the example of an employee in the pharmaceutical industry who fails to report a defect in the company's product. The employee's perception of the situation may differ if the problem with the quality of the drug leads to the death of the patient or makes the treatment ineffective. The more negative the anticipated consequences of the behavior on others, the more severe/serious the act will be perceived to be and the more individuals are going to feel moral dissonance.

Experiencing moral dissonance generates significant psychological discomfort compared to situations of dissonance with no moral content (Kelman and Baron 1974). Indeed, the more significant the cognition inconsistent with behavior is for the individual, the greater the dissonance he/she will experience (Festinger 1957; Travis and Aronson 2015). This is particularly the case with values and moral principles constituting crucial cognitions for individuals. The inconsistency between the problematic behavior and moral values results in negative emotions such as guilt and shame which are threatening to one's sense of self (Kelman and Baron 1974, Steele 1988, Umphress and Bingham 2011). As Kelman and Baron (1974: p.561) state: "The violation of an 
important moral precept or the negation of an important value carries direct implications for central aspects of the person self-image. That is such an inconsistency affects both a person's basic sense of worth and his belief as to his defining attribute". The individual, then, seeks to preserve an image of a coherent, reliable, competent and moral person (Travis and Aronson 2015; Tsang 2002). The motivation to reduce moral dissonance is, therefore, particularly strong.

\section{Modes of moral dissonance reduction}

Faced with the state of psychological tension, individuals will try to reduce dissonance through different modes. According to the traditional theory of cognitive dissonance (Festinger 1957), the inconsistency between behaviour and cognition can be mitigated in several ways. Individuals can either change their behaviour, or resort to cognitive rationalization which consists of modifying inconsistent cognitions (including attitude), adding new ones or minimizing the importance of the cognitive elements in conflict (trivialization) ${ }^{2}$. To reinforce his or her attitudes, opinions, or decisions, the individual can also seek social support by surrounding himself or herself with people who share his or her point of view and avoiding those who disagree (Festinger 1957). Social support is, then, a means of reducing dissonance and an alternative to attitude change (Voisin et al. 2013). However, these mechanisms are not always effective in reducing dissonance and individuals are sometimes forced to continue to live with the psychological discomfort. This can lead them to situations of avoidance of dissonance in the future; they do so by refraining from making decisions in contexts similar to those that led them to experience dissonance (Festinger 1957).

Modes of moral dissonance reduction are specific (Holland et al. 2002; Lowell 2011). On the one hand, although most individuals would like to act ethically, moral behavior is frequently costly and it can be tempting to act unethically from the standpoint of self-interest (Tsang 2002; Gunia et al. 
2012). It will therefore be easier for individuals to alter their dissonant cognition (generally, their attitude) than modify their behavior (Festinger 1957). On the other hand, when an attitude is strongly salient to an individual, it can hinder the path of attitudinal change and lead to the adoption of alternative modes of cognitive reduction (Simon et al. 1995; Voisin et al. 2013). This is particularly the case when the problematic act violates important social standards such as moral principles (Tsang 2002). Faced with this uncomfortable situation, individuals can resort to trivialization (Simon et al. 1995). They can also add new cognitions such as self-justifications to the existing cognitions in order to reduce the dissonance (Gosling et al. 2006; Travis and Aronson 2015; Voisin and Fointiat 2013) without changing either behavior or attitude.

Tsang (2002, p.34) describes very clearly the ethical conflict experienced and the psychological processes at work to resolve it: "When the moral relevance of their behavior becomes salient, individuals are faced with motivational conflict. One can choose to behave in line with one's moral principle, but often moral action is costly and one's competing motivation may be strong. However, violating moral principles is also costly. It is at this point that the individual can reduce the cost of acting immorally by engaging in moral rationalization". The main way to reduce moral dissonance is, therefore, through moral rationalization, also termed self-justification (Holland et al. 2002; Lowell 2011; Travis and Aronson 2015) ${ }^{3}$. However, little research has been done so far on the nature of the self-justifications used to deal with moral dissonance.

According to Holland et al. (2002), the type of self-justification used depends on the type of dissonance. In an experimental study of moral dissonance encountered with regard to an everyday act (using one's own car instead of public transport, even though it is more polluting), he finds that the self-justifications are essentially external. That is, individuals mostly justify the consequences of their actions by referring to external causes. These include lack of personal control over the situation and social pressure or displacement of the responsibility on to others. Indeed, the fear of 
social disapproval may be more important when the problematic behavior is likely to result in harmful consequences for others, which is the case with moral dissonance. Therefore, people need to restore their self-image by absolving themselves of responsibility.

In his conceptual model focusing on business ethics problems, Lowell (2011) proposes a set of self-justifications which are mainly external and largely based on the organizational context. Lowell specifically identifies two main justification mechanisms. The first is normalizing/ routinizing the immoral act by trivializing and ignoring its consequences through a focus on the details of the execution process (Lowell, 2011). Ashforth et al. (2007) illustrate another way of normalizing professional behaviors, when in order to maintain a positive identity, employees in morally controversial occupations emphasize positive aspects of their work and/or deny its negative aspects. The second mechanism is blaming/dehumanizing the victims of the act (Lowell 2011). Not only do these self-justifications help unethical behaviors to become institutionalized in organizations, as suggested by Tsang (2002) and Ashforth and Anand (2003), but they can lead to escalation of the unethical act, for instance when blaming victims is used to justify an act of violence against them, resulting in a further attack (Travis and Aronson 2015).

This work is an important step forward in understanding how individuals rationalize their unethical acts, but it remains at the margins of the field. Moreover, the experimental methodologies adopted by the few existing empirical studies do not make it possible to account for the richness and diversity of self-justifications in the case of moral dissonance, particularly in an organizational context. In this respect, the neutralization theory (Sykes and Matza 1957) seems particularly useful to better understand the phenomenon of rationalization in the face of moral dissonance. Indeed, while there is currently no exhaustive typology of the self-justifications adopted in the face of moral dissonance, the neutralization theory makes it possible to study these justification mechanisms in depth. 
Neutralization as a strategy to reduce moral dissonance

The theories of dissonance and of neutralization, both formulated in 1957, are considered by several researchers to be twin theories (Maruna and Copes 2005). Even though they arose in different disciplines, respectively social psychology and the sociology of deviance, both theories aim to understand the cognitive process involved when an individual's behavior is inconsistent with his/her beliefs, values or social norms (Maruna and Copes 2005; Ribeaud and Eisner 2010; Divard 2013). Neutralization theory provides valuable insight into the nature of the self-justifications mobilized (Maruna and Copes 2005; Odou and Bonnin 2014). According to this approach, when an individual adopts behavior that deviates from the dominant social norms to which he is nevertheless attached, he or she will resort to justification mechanisms that protect himself or herself from moral condemnation; reduce guilt; and preserve self-esteem. Sykes and Matza (1957) were the first to explicitly use the concept of techniques of neutralization in their paper "Techniques of neutralization: A theory of delinquency" and to propose a typology based on five categories ${ }^{4}$ (Table 1). Although various authors have proposed expanding Sykes and Matza's five original techniques (cf. in particular Ashforth and Anand 2003; Cromwell and Birzer 2012; McGregor 2008; Minor 1981), the initial typology remains the standard reference, since the many techniques added over the years are very similar to the original categories (Chatzidakis et al. 2007).

Several authors have explained how neutralizations help to reduce cognitive dissonance, identifying which type of dissonance reduction mode they correspond to (Chatzidakis et al. 2007; Cromwell and Birzer 2012; Divard 2013; Heath 2008). They actually consist of adding new cognitions that make it possible to prevent or reduce dissonance without changing either attitude or behavior "In neutralization theory, the techniques aim to restore balance, not by erasing the 
distance between belief and behavior but by temporarily lifting the norm by adding an additional discourse that enables practice to be dissociated from the norm." (Odou and Bonnin 2014, p.106)

Table 1: Neutralization techniques of Sykes and Matza (1957)

\begin{tabular}{ll}
\hline Technique & Definition \\
\hline $\begin{array}{l}\text { Denial of } \\
\text { responsibility }\end{array}$ & $\begin{array}{l}\text { Individual are not personally responsible for their deviant actions } \\
\text { and are subject to forces beyond their control. }\end{array}$ \\
\hline Denial of injury & $\begin{array}{l}\text { The deviant behavior is not serious and has little or no harmful } \\
\text { consequences for others. }\end{array}$ \\
\hline Denial of the victim & $\begin{array}{l}\text { There are no victim or the victims are responsible for what happens } \\
\text { to them, or even deserve it. }\end{array}$ \\
\hline $\begin{array}{l}\text { Condemnation of the } \\
\text { condemners }\end{array}$ & $\begin{array}{l}\text { Those who condemn acts are guilty of the same conduct themselves } \\
\text { or are hypocrites. }\end{array}$ \\
\hline $\begin{array}{l}\text { Appeal to higher } \\
\text { loyalties }\end{array}$ & $\begin{array}{l}\text { The demands of society are sacrificed by the individual to meet the } \\
\text { expectations of smaller groups to which they belong or by } \\
\text { conforming to norms deemed to be higher. }\end{array}$ \\
\hline
\end{tabular}

The concept of neutralization can be applied to any form of deviance by accounting for the ways human beings manage the inconsistency between their beliefs and behavior when they violate social, legal, or ethical norms (Maruna and Copes 2005). This interpretation grid is, therefore, applicable to professionals caught in ethical conflicts. In particular, it has been mobilized to examine the ethical decision making of marketing practitioners (Serviere-Munoz and Mallin 2013; Vitell and Grove 1987; Sachet-Milliat et al. 2017).

Finally, there has been little research on moral dissonance within the organization and its different modes of reduction. Because of the experimental methodologies adopted, the modes of dissonance reduction are not related to the context-whether it is their position in the organization or their emotional feeling of dissonance-of the individuals who experience it. Further, these methodologies prevent an understanding of the complexity and the variety of the strategies mobilized by the same individual. We propose to study in a more exhaustive way the strategies deployed by pharmaceutical industry marketers in the face of the ethical conflicts. How do they 
reduce their moral dissonance? What strategies do they use, including selfjustifications/neutralizations?

\section{Methodology}

For our data collection, in accordance with the comprehensive aim of our study, we adopted a qualitative method. We chose the narrative interview method because it allows us to analyze in depth individuals' ethical reasoning (Maruna and Copes 2005). It gives the respondent some autonomy to express him/herself freely on subjects requiring a degree of introspection. In order to explore the moral dissonance that marketers may face due to the tension between profit and health in their sector, we asked our respondents to tell us about episodes experienced in the context of their professional activity that may have worried their conscience (see the interview guide in Appendix 1). To further enrich these narratives and encourage the reflexivity necessary for ethical scrutiny, we made known our question to respondents prior to the interview. To limit social desirability bias, we made no mention at any time of the inherent tension in the pharmaceutical sector. In addition, given the sensitive nature of our research, we were obliged to take certain precautions, both to access the field and to collect the narratives (Appendix 2).

Eighteen marketers working or having worked in the pharmaceutical industry in France were interviewed (Appendix 3). There are two reasons why France provides an interesting context for analyzing how marketers reconcile health and economic missions in the course of their work. First, the regulations in place are particularly strict with regard to medicines. Unlike the Anglo-Saxon countries, these are distributed exclusively through pharmacies, even when they are not prescribed drugs. Price monitoring applies to a large number of products involving reimbursement to users by the state. Direct-to-consumer advertising is subject to approval by an independent authority. The 
second reason is that the pharmaceutical industry in France is controversial due to the many scandals that have arisen, among which the Mediator scandal (a drug produced by the Servier laboratory) generated the most media coverage. First authorized on the French market for diabetics and people suffering from hypercholesterolemia, Mediator was diverted from this use and prescribed to other (non-diabetic) patients as an appetite suppressant for weight reduction, despite its negative side effects on the heart valves. The drug was withdrawn in France almost 10 years after other countries, suggesting that the laboratory involved knew of its dangers. The number of deaths is estimated at 2,000, with 9,000 victims claiming compensation. As a result, only $49 \%$ of French people trust the pharmaceutical industry ${ }^{5}$.

All our interviewees have worked in marketing or sales jobs closely related to marketing. Some of them progressed to sales or general management positions, while keeping their marketing prerogatives. The profiles are varied in terms of gender ( 7 men and 11 women) and professional experience (minimum 3 years and maximum 30 years). Ten of the interviewees have worked in several pharmaceutical companies. Five have left the sector.

The interviews conducted lasted an average of one hour per respondent. Interviews were then fully transcribed, producing a corpus of 126,129 words (Appendix 4). Most respondents reported an instance of conflict and some of them a number of instances. In all, 18 cases were reported and analyzed.

The data were coded using NVivo12 qualitative analysis software. First, we carried out a thematic coding according to the themes of the interview guide. In addition to the interviewee's professional background, we also coded his/her narrative of the case of conscience, justifications invoked, and perception of the sector. In a second step, we proceeded to the analytical coding of the narratives according to our conceptual framework: moral dissonance theory and neutralization theory. The 
coding grid used to analyze the strategies for reducing moral dissonance is provided in Appendix 5.

To strengthen the reliability of our analysis, our analytical coding was done in several steps:

- A first coding was carried out jointly by two researchers to stabilize the coding grid (for $25 \%$ of the corpus studied). Then the rest of the coding was performed by one of the authors.

- A double coding involving a third researcher was carried out to validate the robustness of the grid (on an additional $25 \%$ of the corpus studied). This highlighted the difficulty of differentiating between certain categories of justification, such as "denial of damage" and "denial of victims", because of the possible overlap between them, as identified by other authors (Divard 2013). Finally, convergence was obtained (with an inter-coder agreement rate of 90\%).

In a third step, a final reading was carried out for each respondent in order to identify the overall logic of their discourse and to compare it with that of others, following the grounded theory method (Strauss et al. 2004): systematic comparisons, etc. This step led to the identification of different strategies implemented by respondents to address dissonance and suggested that these strategies could be linked to the severity of ethical conflicts.

We therefore conducted a final analytical coding to assess the severity of ethical conflicts reported by our respondents. For this purpose, we decided to use the concept of moral intensity developed by Jones (1991). Moral intensity is a multidimensional construct that relates to issues in terms of their perceived moral significance (Barnett, 2001). It comprises six dimensions, namely magnitude of consequences, social consensus, probability of effect, temporal immediacy, proximity with victims or beneficiaries, and concentration of effect. We selected the first five dimensions because the last (concentration of effects) did not seem relevant for ethical problems related to health. As Jones explains "measurement of moral intensity and its components is probably possible only in terms of relatively large distinctions". In this regard, for each dimension we tried to distinguish 
gradations from 0 to 3 . Appendix 6 details the criteria we used to assess each dimension. We then added the scores for the five dimensions and arrived at an overall assessment per case ( 0 to 15$)$.

\section{Results}

Our results show that marketers experience various ethical conflicts linked to the dual economic and health mission specific to the pharmaceutical industry. The perceived severity of these ethical conflicts varies among respondents, thus manifesting moral dissonance to a different extent. As a result, the following strategies were used to deal with dissonance, each combining several dissonance reduction modes (Appendix 7): 1) minimize the sensitivity of their activity; 2) refer to the patient benefits; and 3) avoid problematic situations. After presenting the different types of ethical conflicts experienced by our respondents in Section 1, we detail the strategies in Section 2.

\section{Ethical conflicts experienced by marketers in the pharmaceutical industry}

Our respondents relate various ethical conflicts linked to the dual economic and health mission specific to the pharmaceutical industry. By ethical conflict, we mean concrete and specific cases

personally experienced by our respondents. Respondents sometimes expressed general unease or referred to general issues (for example the complexity of setting a fair price) without mentioning specific cases: we considered then that they reported "no case" (Table 2). Cases that are not specific to the pharmaceutical context (such as management problems) were eliminated. The ethical issues raised by our respondents relate to offers with different regulatory statuses: from simple vitamins sold in pharmacies without prescriptions to products that can be administered for serious diseases within hospital neurological services by prescription medicines. They are mainly concerned with promotion policy and product policy. 
Table 2: Description and classification of ethical conflicts reported by respondents

\begin{tabular}{|c|c|c|c|}
\hline $\begin{array}{l}\text { Rid* } \\
(\mathrm{Cid}) * *\end{array}$ & Type of offer & Description & $\begin{array}{l}\text { Ethical } \\
\text { intensity }\end{array}$ \\
\hline R1 (C1) & $\begin{array}{l}\text { Non prescribed } \\
\text { (nicotine } \\
\text { substitutes) }\end{array}$ & $\begin{array}{l}\text { Modify the packaging of the product by making it more } \\
\text { attractive so that it is more used to stop smoking at the } \\
\text { risk of developing misuse among young consumers. }\end{array}$ & Low \\
\hline R1 (C2) & $\begin{array}{l}\text { Non prescribed } \\
\text { (analgesics, sore } \\
\text { throat) }\end{array}$ & $\begin{array}{l}\text { Encourage pharmacists to order drugs in very large } \\
\text { quantities in exchange for discounts and gifts. In this way, } \\
\text { the pharmacist is in a position to recommend to his } \\
\text { customers the product that is most economically attractive } \\
\text { to him rather than the best suited to the patient from a } \\
\text { therapeutic point of view. }\end{array}$ & Low \\
\hline R2 & $\begin{array}{l}\text { Medicines (all } \\
\text { types) }\end{array}$ & No case. & n.r. \\
\hline R3 (C3) & $\begin{array}{l}\text { Prescribed } \\
\text { medical devices }\end{array}$ & $\begin{array}{l}\text { Decide whether or not to continue to market a product that } \\
\text { has caused very severe side-effects but still offers } \\
\text { significant benefits to patients. }\end{array}$ & High \\
\hline R3 (C4) & $\begin{array}{l}\text { Prescribed } \\
\text { hospital material } \\
\text { (neurology) }\end{array}$ & $\begin{array}{l}\text { Promote new therapeutic indications for children in severe } \\
\text { neurologic pathologies despite not authorized by } \\
\text { regulation through a scientific symposium for physicians. }\end{array}$ & High \\
\hline $\mathrm{R} 4$ & $\begin{array}{l}\text { Medicines (all } \\
\text { types) }\end{array}$ & No case. & n.r. \\
\hline R5 (C5) & $\begin{array}{l}\text { Prescribed } \\
\text { medicine } \\
\text { (analgesics) }\end{array}$ & $\begin{array}{l}\text { Organize a public relations operation to communicate on a } \\
\text { molecule by praising its absence of side effects despite it } \\
\text { is a medicine with potential side effects. }\end{array}$ & Medium \\
\hline R5 (C6) & $\begin{array}{l}\text { Prescribed } \\
\text { medicine } \\
\text { (analgesics) }\end{array}$ & $\begin{array}{l}\text { Ask medical sales representatives to position an anti- } \\
\text { inflammatory molecule as an analgesic to hide its side } \\
\text { effects. }\end{array}$ & Medium \\
\hline R6 (C7) & $\begin{array}{l}\text { Prescribed } \\
\text { medicine (all } \\
\text { types) }\end{array}$ & $\begin{array}{l}\text { Practice illegal discounts with pharmacists, offer overpaid } \\
\text { services to bypass discount levels. }\end{array}$ & Low \\
\hline R7 (C8) & $\begin{array}{l}\text { Prescribed } \\
\text { medicines (heart } \\
\text { disease) }\end{array}$ & $\begin{array}{l}\text { Promote a treatment sold by the pharmaceutical company } \\
\text { rather than a surgical procedure at the risk of } \\
\text { compromising the principle of scientific objectivity }\end{array}$ & High \\
\hline R8 (C9) & $\begin{array}{l}\begin{array}{l}\text { Dietary } \\
\text { supplements }\end{array} \\
\end{array}$ & $\begin{array}{l}\text { Launch the sale of a new product too quickly and take the } \\
\text { risk of uncontrolled side effects. }\end{array}$ & High \\
\hline R9 & $\begin{array}{l}\text { Non prescribed } \\
\text { medicines }\end{array}$ & No case. & n.r. \\
\hline R10 (C10) & Vitamins & $\begin{array}{l}\text { To enhance sales, do not recall the warning regarding } \\
\text { pregnant women during product demonstrations to } \\
\text { consumers. }\end{array}$ & High \\
\hline R10 (C11) & $\begin{array}{l}\text { Slimming } \\
\text { products }\end{array}$ & $\begin{array}{l}\text { Promote a product in pharmacies whose side effects have } \\
\text { not been evaluated especially on pregnant women. }\end{array}$ & High \\
\hline R11 (C12) & $\begin{array}{l}\text { Non prescribed } \\
\text { medicines }\end{array}$ & $\begin{array}{l}\text { As a sales representative, talk to the pharmacist about the } \\
\text { product's characteristics' despite you are not allowed to } \\
\text { do so. }\end{array}$ & Low \\
\hline R12 (C13) & $\begin{array}{l}\text { Medical devices } \\
\text { (lenses) }\end{array}$ & $\begin{array}{l}\text { Develop a sales pitch for the physician regarding a } \\
\text { product that can lead to perform additional surgical } \\
\text { operations depending on the quality of the material. }\end{array}$ & Medium \\
\hline R13 & $\begin{array}{l}\text { Medicines (all } \\
\text { types) }\end{array}$ & No case. & n.r. \\
\hline R14 (C14) & $\begin{array}{l}\text { Prescribed } \\
\text { medicine }\end{array}$ & $\begin{array}{l}\text { Market of a product with dangerous side effects for the } \\
\text { patient and a risk of misuse by physicians. }\end{array}$ & High \\
\hline
\end{tabular}




\begin{tabular}{llll}
\hline $\begin{array}{l}\text { Rid* } \\
\text { (Cid)** }\end{array}$ & Type of offer & Description & $\begin{array}{l}\text { Ethical } \\
\text { intensity }\end{array}$ \\
\hline R16 (C15) & $\begin{array}{l}\text { Prescribed } \\
\text { medicine }\end{array}$ & Market medicines despite no true interest for the patient. & Medium \\
\hline R16 (C16) & $\begin{array}{l}\text { Prescribed } \\
\text { medicine }\end{array}$ & $\begin{array}{l}\text { Financially contribute to scientific symposiums involving } \\
\text { physicians as key opinion leaders in order to get favorable } \\
\text { therapeutic recommendations for the laboratory. }\end{array}$ & Medium \\
\hline R17 & $\begin{array}{l}\text { Prescribed } \\
\text { medicine }\end{array}$ & No case. & n.r. \\
\hline R18 (C17) & $\begin{array}{l}\text { Prescribed } \\
\text { hospital medical } \\
\text { material }\end{array}$ & $\begin{array}{l}\text { Minimize the feed-back of vigilance material to be able to } \\
\text { communicate on a risk-free product. }\end{array}$ & High \\
\hline R18 (C18) & $\begin{array}{l}\text { Prescribed } \\
\text { medicine (care } \\
\text { cream) }\end{array}$ & $\begin{array}{l}\text { Promote a product for children with carcinogenic risks but } \\
\text { likely to relieve them of a pathology generating a strong } \\
\text { handicap. }\end{array}$ & High \\
\hline
\end{tabular}

$* \mathrm{R}$ id: Respondent identification

** C id: Conflict identification

These conflicts are experienced by our respondents as varying in severity. By coding their moral intensity, we obtained three categories of ethical conflict: low, medium and high intensity. Ethical conflicts of low moral intensity include issues in relation to packaging and to sales promotion (e.g., minor violation of rules such as illegal discounts). For example, R11 explained that although sales representatives are not supposed to present product characteristics to pharmacists, because they are not qualified for this, he did so regularly. With regard to conflicts of medium intensity, respondents reported deliberately hiding or minimizing mild side effects, or creating privileged relationships with doctors with the aim of influencing them. For example, R16 has been supporting physicians who are key opinion leaders in order to obtain favorable therapeutic recommendations for the laboratory. High intensity conflicts variously involve lack of transparency on product quality issues, lack of scientific objectivity in order to advantage the company's products, deliberately hiding or minimizing serious side effects, lack of caution in the prior analysis of potential adverse effects, downplaying risks of potentially severe side effects, etc. For example, R3 is involved in marketing a product that has harmful side effects, to the point of causing a scandal in the press. The distinction between these different degrees of moral intensity is based on the information provided by our respondents in marketing and their sense of the seriousness of such potential side 
effects. Such perceptions are subjective and can vary from one marketer to another for the same type of issue.

Our analysis led us to distinguish three types of strategies implemented by marketers to cope with moral dissonance, in relation to the severity of the ethical conflicts they encounter and consequently the type of moral dissonance they experience. The following sections detail the various strategies used by marketers, each consisting of a combination of several dissonance reduction mechanisms.

\section{Three distinct strategies for managing moral dissonance}

\subsection{Minimizing the sensitivity of their activity}

In this first strategy, marketers do not report any situations of ethical conflict or refer only to issues of rather low severity. They thus express little or no moral dissonance. They consider there to be no contradiction between the health mission and the economic dimension of their profession, and this allows them to accept its economic aspects. The justifications invoked are largely based on minimizing the sensitive nature of the activity and on the argument of economic necessity.

\section{(a) Ethical conflicts and moral dissonance}

The few problems addressed are of relatively low intensity and do not directly impact patients. Hence the marketers do not express any moral dissonance associated with the dual mission of the pharmaceutical industry. In their view, the two objectives pursued by the sector (health and profitability) are not contradictory. Respondents talk about the economic objectives of their activity without any embarrassment. The pursuit of profit is essential because the pharmaceutical industry is operated by private companies. 
"Either you think: the pharmaceutical industry is an industry, so it is there to make money and make money for our shareholders and be profitable. Or you don't accept it: you think that health is something in the public domain and then you'd have to change the model in all countries." (Interview 4)

Profitability is necessary for the successful completion of the health mission. From this standpoint, far from being in opposition, the economic and health objectives converge, with the former serving the latter. This non-contradictory view enables respondents to have a very positive perception of their profession and their sector of activity. They emphasize their key economic role in people's health and well-being.

"We're the major investors in tomorrow's health care. Ultimately, when we see... we're going to say the players who are investing today for the 'drugs of tomorrow', in quotes, they're the pharmaceutical companies." (Interview 13)

However, while they do not express any discomfort in working in the pharmaceutical industry, some report that their sector suffers from a negative image either in the media, among their entourage, or in their wider social circle. As such, they are regularly criticized by people who do not work in it.

"But it's more like... friends, relatives who don't work in a pharmaceutical laboratory, who are in other disciplines... So, in fact, it's just that they say I am 'bad', thinking that... well, what we do is just... to make more money by not being ethical precisely." (Interview 13)

(b) Modes of reducing moral dissonance

Although respondents report few cases of specific ethical conflicts, their comments present many neutralization techniques to justify the absence of significant problems : denial of injury, appeal to higher loyalties, and condemnation of the condemners.

Neutralization based on the denial of injury

A first type of justification consists of minimizing or even denying the potentially problematic nature of their activity; this can be compared to the "denial of injury" technique of neutralization. 
Different arguments are used. First, respondents note that scandals reported in the press are exceptions and should not be generalized.

"I would say there may be bad students. But, in any case, I, from what I have seen, and from what I have practiced, [... think] there is still a lot of ethical behavior, eh, in the pharmaceutical industry. We're not... it's not a brigands' den that does anything it wants. It's the other way round. There are more and more standards, more and more standards and procedures." (Interview 15)

In addition, to minimize the damage that their business can cause, respondents argue about the strict regulation of their sector. In particular, the additional measures put in place following major health scandals have made it possible to better control and avoid abuses in the sector.

"There is no longer any problem because everything has been regulated. So, the problems of conflict of interest as in Servier, ${ }^{6}$ it's over. It can't happen anymore... And so, today, it's really changed, really changed"..."There was really one before and one after [Servier], it's really changed." (Interview 6)

They also claim that the reliability of their products, which have been approved by the health authorities, and are sold through channels controlled by health professionals (pharmacists).

"On the pharmaceutical circuit... you still have to go to the counter and generally the health professionals in pharmacies do a good job of asking for contraindications or if people are already taking treatment. So, we're going to say the personal ethical impact is a little less strong, even almost non-existent... And beyond that, it's products that have been validated by the ANSM ${ }^{7}$ for that, so I have no problem with that." (Interview 11)

Marketers underline the seriousness of their organization in complying with the rules and setting up procedures to control risks. In this context, the decisions taken seem perfectly controlled.

"Maybe it's the structure in which I work that is perhaps also hyper... that really makes sure that we respect strictly the regulations and even prefer to protect ourselves even more against the regulations. So maybe it's the structure that makes me say: 'yes, indeed we don't take any risks'." (Interview 13)

The regulatory department plays a key role. It provides a safeguard for marketers by ensuring that their actions comply with regulations.

"Now, I'll add to that, that being in the drug, and having the regulations helps a lot in preventing you from doing anything stupid... It's true that regulation and having other teams in a company that don't have a direct sales interest, it helps to balance the points of view and leads to something more reasonable." (Interview 1). 
Finally, some rely on the harmlessness of their products on the grounds that they are comfort treatments or products marketed for years without any change in their formula.

"I think it's because I've never worked in very heavy treatments either, you know. I've always been in 'boo-boology' [minor health issues]... on treatments that in the end, you know, it only feels good. Because... I mean, they are not life-saving treatments, you know." (Interview 6)

Neutralization based on the appeal to higher loyalties (the economic necessity)

Respondents also use the technique of appealing to higher loyalties. In doing so, they essentially refer to the economic standard that they present as necessary, if not superior, to the pursuit of the health mission. These respondents emphasize economic arguments. The pursuit of profit is presented as a necessity, especially because the industry requires significant investment in $R \& D$, personnel, and equipment.

"I have to pay the employees every month. I have to repay a loan to a bank and so... today it is almost a matter of survival for me to be able to charge for the services I provide to my main customers and to the community." (Interview 2)

In their narratives, respondents make extensive use of a financial register (profitability margin, volume, etc.) to show the relentless nature of the economic logic from which there is no escape. They also underline the beneficial effects of their activity in terms of employment.

"Such a product employs so many people in such a city, mathematically, we have more... Without the product, we no longer have the volumes. So, that means closing the plant." (Interview 17)

The financial profitability of the pharmaceutical industry is also presented as a considerable advantage because the profits are used to finance medical research.

The high cost of some treatments is justified by the benefits they bring to patients: health has a cost.

"But if you pay 6500 per eye [to pay for an innovative treatment], which is a lot, but in fact over a life-time it's not very expensive...that's it, you won't need glasses any more or practically never." (Interview 12) 
The economic dimension of pharmaceutical companies, particularly the high prices of treatments that guarantee the profits of the pharmaceutical industries, allows them to fulfill their health mission.

\section{Neutralization based on the condemnation of the condemners}

As a third form of neutralization, respondents defend themselves against criticism of their sector by other stakeholders such as regulators, or journalists, by highlighting their lack of integrity or inconsistency.

"Oh yes, about V. [a medicine], yes. But it's not new, it's just to create buzz, it's not new what's coming out right now. It's not new in fact, these studies... It's something that's been well known to the medical profession for years in fact. It's just that maybe that's all the journalists have to get their teeth into right now." (Interview 13)

"I thought good: as long as the legislator closes his eyes and is a little hypocritical, well, in the end I'm still comfortable with my conscience, you know what I mean?" (Interview 6)

\subsection{Invoking patient benefit}

In contrast to the previous case, some conflicts may involve significant health risks and are thus experienced as severe, leading to strong moral dissonance. Most of these conflicts are experienced as dilemmas in which the marketers hesitate between two alternatives. Their resolution is based on arguments about the benefit to the patient. The economic dimension is under-represented in the respondents' discourse. In these critical situations, marketers embark on an intense resolution strategy that combines neutralization and the search for social support.

\section{(a) Ethical conflicts and moral dissonance}

These ethical conflicts concern situations in which marketers' mission is in conflict with the patient's interest. This is the case when they contribute to the promotion of a product that is potentially harmful to patients. The conflicts reported are experienced as severe. 
Most of these conflicts take the form of complex situations where respondents have difficulty deciding on the right choice to make. For example, R8's conflict is described as a struggle between two irreconcilable options: continue the launch preparation of a new product for the benefit of his company because of the considerable resources deployed so far in terms of time and money, or stop it for the benefit of patients and protect them from the risks of insufficiently tested adverse effects. Such conflicts are accompanied by doubts and many questions both before and after the decision is made.

"And at the end, we say to ourselves: "But are we really going to have the right to say that?". It's really very schizophrenic...the regulations, they're afraid of their own shadow. So, we say to ourselves:" Is this event?... yes, it's good. But are we allowed, is it legitimate? Aren't we going right into the wall?" (Interview 7)

These situations lead to significant moral dissonance: respondents express a feeling of discomfort, linked to uncertainty about having made the right decision and concern about harmful repercussions.

"I started things, and, and, and, it really worked for me for a while. We really need to do this because the product is not yet on the market, there may still be time to apply the brake. And so ... these doubts.... they worked on me for two months after that. The two months between the creation of the product and the launch of the product..." (Interview 8)

These complex situations are centered on patients, and weighing up the risks and benefits for them.

Finally, patient benefit is presented as a determining criterion in the face of these difficult decisions.

"And then, it's true when you look at the bright side, it was really super helpful for some of the target patients. So, I think that, personally, I was certainly more driven by the benefit versus the risk side ... in the end, we're going to treat people who couldn't be treated before..." (Interview 14)

These marketers have a different perception of the articulation of health and economic objectives, from the previous perspective. In contrast to the first case, they avoid talking about the economic dimension of their activity and underline the health mission pursued. Thus, even when they mention financially interesting projects, the respondents insist, above all, on the benefit of their offer from a medical point of view.

"There are a huge number of patients who suffer from it... So, there is a very, very large market, shared by 4 or 5 labs and then the lab is confident that it will launch its drug and achieve a good 
market share... And the patient, it is also beneficial to him and the general practitioners and pharmacists... So yes, the goal is still moral and loyal, and it is a great project." (Interview 7)

These situations of dissonance, which are lived as tough choices to make and generate deep discomfort, are nevertheless limited to specific problematic situations. The respondents do not question the vision that they have of their profession. Despite the problems encountered, these marketers see value in the pursuit of their medical mission.

\section{(b) Modes of reducing moral dissonance}

In order to cope with this strong moral dissonance, marketers deploy several reduction methods. In addition to the justifications provided, they describe many interactions with other stakeholders that can be compared to the mechanism of seeking social support.

\section{The search for social support}

Social support takes many forms. It is carried out internally within the organization through formalized discussions between different functions: the regulatory department, the pharmacist responsible, $\mathrm{R} \& \mathrm{D}$, and general management. This discussion is seen as an aid by the marketers because it allows them to control their activity and prevent them from transgression.

\footnotetext{
"But when we were working on the key messages, we were actually doing it in a project group with people from different backgrounds... but then inevitably, when you're a marketer, sometimes you want to push the thing a little harder. And then, the regulatory: 'you can say it like that, we can say it like that'." (Interview 14)
}

In some cases, this discussion is not possible because of internal conflicts that can divide the organization-a source of suffering for the marketers concerned. They do not have any interlocutors with whom they can share the burden of a difficult decision.

"The person I could have discussed it with was the pharmacist in charge, because safety is more her area...but we hated each other. So, it was impossible to have a frank dialogue and say: 'here's the thing about this project. I still have doubts about safety, here's the thing, what do you think?"' (Interview 8) 
Marketers may also seek social support outside the organization. Using the opinion of external experts (doctors) allows them to rely on the guarantee of these experts to legitimize a difficult decision.

"I supported myself, with a certain number of serious surgeons, not surgeons who wanted to make money but serious surgeons..., who had 15, 20 years of hindsight behind them, who explained what. And so, it made me... I was quite comfortable, I was comfortable, but I had to find reasons myself to continue. But today I'm comfortable." (Interview 3)

Respondents can also consult those in their personal circle. This support allows them to move beyond the organization's consensus to develop a strong conviction. For example, a respondent may seek social support from her relatives, who are concerned about the pathology targeted by the product she is marketing. She is relieved to learn that her loved ones are willing to accept the risks associated with the treatment because of the benefit they receive.

"I was fortunate to have people around me who had atopic dermatitis [a condition targeted by the respondent's marketed drug] and in fact I interviewed them... I did my little investigation to find out if, at the time, there had been these treatments, what would they have done for their child? And she [said] ... but in fact it was so complicated for her daughter to go to school that even with an associated risk, she would have taken it, in fact." (Interview 18)

This process of interaction with other internal and external stakeholders - with the aim of ensuring decisions that comply with both regulatory and health constraints—can also lead to a form of disempowerment of marketers who hide behind the collective process or the words of experts (doctors, regulators) to justify risky actions. Responsibility becomes collective and is no longer the responsibility of an individual. This phenomenon of dilution of individual responsibility in the collective is accentuated by the large number of stakeholders involved, both internally and externally.

"Yes, in terms of collective responsibility, I think we haven't been perfect, certainly... But I think that in the cascading of messages, to all people, there may not have been enough...alerts to people, for example medical sales representatives, people who went to hospitals. We certainly had to fail at some point... I mean, I don't know exactly at which point..., but there was a failure in the transmission of messages..." (Interview 14) 


\section{Neutralization based on the appeal to higher loyalties (Invoking patient benefit)}

In parallel to this intense search for social support, respondents mention the benefit received by patients to justify the risky actions. Their discourse is, thus, in line with the technique of neutralization involving an "appeal to higher loyalties." It consists of justifying oneself morally in the name of the noble mission of health that they serve. Respondents' justifications largely involve patient benefit. For example, a case presents the fact that a product could have been used at twice the regulated dose on children suffering from serious diseases and promoted as such in a symposium. To explain this decision of promoting it in that way, the respondent invokes therapeutic benefits, while the economic interest is hardly mentioned.

"You think, you see, even if it's a product that's dangerous, potentially dangerous, on which you don't have too much distance... I was outside the AMM, ${ }^{8}$ it's a decision I made with my scientific manager, we decided to support doctors, because there was a therapeutic interest, we did it." (Interview 3)

In addition to patients, some of the marketers interviewed stress that their action is beneficial to different stakeholders, including the medical community, health sector stakeholders, and the community at large. The quest for profit disappears completely from their speeches and is replaced by the mission of general interest that they espouse.

"Because it's still a disease that affects a lot of people and we have to make it known, and it's very important." (Interview 7)

The benefits that their action makes possible are such that they sometimes present themselves as heroes who perform real miracles for their patients.

"Our product was very beneficial to patients, everyone was grateful to us... and we had health professionals telling us: 'our patients are delighted, cholesterol levels are super low, it's great'. And there were patients who told me: 'my doctor has been forcing me to take cholesterol-lowering drugs for 3 years, 4 years, I have pain everywhere, in fact, and I have been taking your products for two months now and not only is my cholesterol level low, but also the pain has vanished'." (Interview 8)

"And the kids would jump around my neck, the parents would jump around my neck, or kids would draw pictures for me afterwards, to thank me. See? See?" (Interview 3)

Thus, by emphasizing the patient benefit, or even the noble dimension of their activity, the mission of marketers and their professional identity ends up merging with that of doctors. 
"And all the AMMs, I'm the one who got them. I was a salesman, it wasn't in my job at all if you want, I got it, I got it, I put the right people in play. And if you want it's something that, uh, I've received e-mails from doctors telling me about the collaboration we could have, about the service I was providing both to the medical community and also to patients. And if you want it when you get this, all the weight is taken off your chest." (Interview 3 )

The well-being of patients is presented as their only motivation, regardless of their financial interest.

"But I wasn't doing it with a view to earning more bonuses, more bonuses and all that. It was to have, to give as many patients as possible access to the product." (Interview 3)

\subsection{Avoiding behavior that conflicts with their values}

This third category concerns mostly severe ethical conflicts perceived by marketers as being imposed on them by their company, putting them in a situation where they have to do things that are contrary to their values. In their eyes, the pursuit of the company's economic objectives is to the detriment of its health mission, thus leading to their disillusionment. Respondents in this category express significant discomfort, and even genuine distress. Even if they resort to denial of responsibility, they can no longer justify themselves when faced with too much moral dissonance. As a result, they avoid dissonant behavior by leaving their job/mission within the company, resigning from the company, or leaving the pharmaceutical industry altogether.

\section{(a) Ethical conflicts and moral dissonance}

The ethical conflicts reported are perceived to be medium to severe. For example, one respondent said that his company does not report all the anomalies pertaining to the use of its products in maintaining its image. This type of situation places respondents in a very uncomfortable psychological situation, in which they are led by their employer to be insincere towards their interlocutors or to promote a product that presents risks for patients. 
"So it's for reasons to do with the [company's]image, that is, in fact, they [employing laboratory] wanted to be able to say that, in terms of scientific communication, there had never been what is called disintegration [i.e., a quality problem in the product sold]....And it was only an image issue... And so, it's true that... when I went out to see the health professionals, I felt very uncomfortable. They landed me with a problem in fact [that I'd have to cover up]." (Interview 18)

Respondents underline the fact that they have no choice when confronted by these ethical issues associated with actions imposed on them by their hierarchy, colleagues or the company rules. This situation may arise even in the case of respondents holding high managerial positions.

"I was summoned by the general management. It was explained to me that it was out of the question for me ever to write in an e-mail that a health professional had reported a problem." (Interview 18)

In these situations, marketers experience strong discomfort related to their feelings of guilt and the feeling that what they are required to do is not in accordance with their values.

"I wasn't very quiet, let's say. Because I felt like I was selling something that might hurt people or be fatal to some others... I didn't feel comfortable when I sold them, I felt a little guilt in fact..." (Interview 10)

Their discomfort can translate into a lack of meaning at work, the feeling of being useless, as marketer for health products. A good medicine does not need marketing to be sold.

"Where I have more doubts is about the usefulness of my job (laughs). If tomorrow it's wiped off the face of the earth, it's not going to make much difference. Because a drug that's really effective, it sells itself, so there's not necessarily a need for marketing for that." (Interview 16)

This lack of meaning is linked to their feeling of being away from the health mission. In effect, they are not in contact with patients, their clients being the doctors. Besides, they have the feeling that the interests of patients take second place to the economic interests of pharmaceutical companies.

"We're not focused enough on the patient... the clients are the doctors, the doctors see fifteen labs a day. So, actually when they talk about prescriptions... they're just going to think about the first and last lab that comes to visit or who invited them to this or that convention. And you lose sight of the patient in all of that." (Interview 16)

Consequently, marketers have no illusions about their company's mission, knowing that the economic dimension is a priority that undermines the logic of health. 
"So, the wallet always comes first, and that aspect bothered me a little bit too. It was always more money, more..." (Interview 10)

Their discomfort is such that it is no longer limited to the delicate situations they encountered; it is, more generally, about working in the sector. This gives rise to a global suspicion of the pharmaceutical industry. It is illustrated, for example, by a mistrust of the speeches developed by salespeople, particularly about "miracle" products.

"Because I know that basically there are a lot of products that are marketed that are not necessarily good for your health......but nowadays, money is getting so big and... I have the impression that organizations do not adhere much to ethics... among people who market products like this [pharmaceuticals]." (Interview 10)

(b) Modes of reducing moral dissonance

\section{Neutralization based on the denial of responsibility}

Marketers who face such situations are aware of possible abuses and take issue with the role played by their hierarchy, companies, and health professionals (doctors, pharmacists). They also hold consumers responsible, because of their lack of vigilance.

"Well, at the same time I was thinking it was written on the vitamin packs. So normally when you buy something from a pharmacist, the first thing you have to do is read the package inserts and see absolutely everything that's written on them." (Interview 10)

The respondents insist on the responsibility of physicians, because they, unlike pharmaceutical companies, deal directly with patients. At the same time, they criticize medical practitioners for their self-interested attitudes or, on the contrary, for their hostility towards pharmaceutical companies.

"You can't talk to the patient, so the doctor is the one who talks to the patient. So, for months I develop a strategy, I develop documents, things that will be useful to them, I set up animations on the stand that are fun. All of this, but in the end when I attend congresses, I see that the only thing that really attracts them [doctors], that interests them, is the samples or the food on the stand..... Either they try to take advantage of the lab, or they don't care, or they see us as the devil incarnate..." (Interview 16)

More generally, these marketers emphasize the responsibility of professionals who have medical competence, unlike them. Physicians and pharmacists both inside and outside the organization are 
medically competent and therefore responsible, unlike most marketers, who have had no medical training.

"I think marketers are a little bit manipulated in pharmaceutical companies... at least when they don't have medical training. But that's often the case. So, when you tell them: 'this molecule that's an anti-inflammatory and it's not well tolerated, well, if you give half a dose, it loses its antiinflammatory properties and it's very well tolerated'. Well, they believe that. ... all the lab endorsements (pharmacists, supervising physicians) say so. So why wouldn't they believe it? Well, they can't have the whole picture on what they're doing." (Interview 5)

\section{Avoid behavior that is in conflict with marketer values}

In this case, because the dissonance is very important, the neutralizations invoked are not effective.

To resolve cognitive dissonance, our respondents are led to avoid problematic behavior. They choose different strategies to avoid being in conflict with their values. First, they may refuse, whenever possible, to carry out the action that is in contradiction with their values. For example, one respondent reported that she assigned unethical tasks to one of her colleagues.

"Well, I figured each of us had... a different level of ethics and... If they were able to look in the mirror at the end of the day, that was fine, but I couldn't do it, so I went to a manager with whom I got along very well, with whom I was honest. I told her: 'I can't do that, so if I have questions saying there's a problem, I won't say anything, I will just ask for the coordinates and pass them to you, but you handle it. I can 't'. And she said to me: 'Okay'.' (Interview 18)

One respondent tried to avoid putting consumers in danger by warning them. She advised her clients to be well informed about the products she was selling to ensure that they were aware of their side effects.

"So I specified that it [the product sold] should be kept for 8 hours only and I told that maybe it would be nice if the women, these women at home, could be given a little more information on the product in order to be able to... to know what exactly they are wearing. But here is the rub; finally, they are so taken in by the desire to slim down that they are not very aware of what they are buying." (Interview 10)

Some respondents end up leaving their jobs or companies to escape dissonance.

"I mean, ethically, really, today I'm in a different lab, that still makes bandages, but suits me much better in terms of ethics." (Interview 18) 
Finally, some leave the pharmaceutical sector. This behavior applies to marketers who are more aware of possible abuses and, thus, denounce the culpability of their superiors, laboratories, and health professionals (doctors, pharmacists).

\section{Discussion and practical recommendations}

Our findings show that in the context of the economic/health tension specific to the pharmaceutical industry, marketers experience moral dissonance with different levels of intensity. Accordingly, they deploy different strategies to deal with it. The first strategy may be likened to an "ostrich policy": minimizing the ethical sensitivity of their activity allows them to experience no, or a low level, of moral dissonance. Secondly, respondents invoke the priority of the health benefit and seek internal and external social support to neutralize severe ethical conflicts generating strong moral dissonance. Thirdly, they avoid conflict situations by changing their mission, company or sector when they experience strong moral dissonance linked to situations they perceive as being imposed on them by their company.

Our study suggests that the concept of moral dissonance, which comes from social psychology, is useful in shedding light on how individuals experience and cope with ethical conflicts related to the mismatch between their values and the organization's expectations (Doblhofer et al. 2019; Kristof-Brown et al. 2005). This is in line with recent trends of research advocating a descriptive, rather than normative, approach to business ethics because the former is more suitable for understanding why even good people can cross ethical boundaries (Bazerman and Gino 2012). More precisely, the use of the moral dissonance concept helps to understand why and how a person in a situation of ethical conflict — and, therefore, moral dissonance - may or may not continue to endure this situation (Lowell 2011). Some people continue to live with dissonance, while others 
are forced to change their problematic behavior. It is, therefore, helpful to explain why individuals adopt unethical behaviors, while remaining committed to their values, such as health enhancement, according to the strategies they use.

Our research contributes to the understanding of concept of moral dissonance and to the deepening of knowledge about the strategies adopted. Grounded in comprehensive qualitative interviews conducted with professionals who told us about issues they experienced at work, our study complements existing work, which is mainly based on laboratory experiments where the experimenter pre-defines the possible dissonance reduction modes (McGrath 2017). Our results capture how marketers experience moral dissonance and the processes spontaneously adopted for reducing it in real organizational settings. We are thereby able to provide a more detailed picture of moral dissonance and strategies developed by individuals who experience it.

The results enrich the concept of moral dissonance. The qualitative methodology adopted allows us to put some flesh on this concept, which until now has been studied in a theoretical or experimental way. It allows us to explain the concrete situations experienced by marketers in the pharmaceutical industry that generate moral dissonance. Our results also shed light on the different levels of intensity of moral dissonance. This contribution is all the more important as most studies do not explicitly investigate the psychological discomfort associated with dissonance (Cooper 2012; Hinojosa 2017). Using the concept developed by Jones (1991), we provide an assessment of the degree of moral dissonance through the perceived intensity of the ethical conflicts that are the source of the dissonance. We distinguish conflicts perceived as having a low, medium or high moral intensity, thus generating low, medium or high moral dissonance (see Appendix 6). In doing so, we empirically confirm Umphress and Bingham's hypothesis that the potential severity of an 
ethical issue influences the level of moral dissonance. Our exploratory analysis calls for additional research to further investigate this relationship.

The analysis reveals three strategies for dealing with moral dissonance. The first involves reducing dissonance by minimizing and even ignoring the ethical problems. This strategy is mainly based on denial mechanisms: marketers either do not report ethical conflicts, or report only very minor ones, in contrast to their extensive use of neutralization to justify their actions. This configuration coupling low intensity ethical conflict with high levels of neutralization has not been reported in the literature. According to Umphress and Bingham (2011), a high level of neutralization is more likely to occur in response to high intensity ethical conflicts. This finding could be explained by the fact that the respondent's failure to perceive any ethical problems results from neutralization (by ignoring potentially disturbing facts). Our results therefore indicate a potential influence of neutralization on perception of the severity of the ethical conflict. This finding has important implications for research in behavioral business ethics, since the intensity of a moral issue is a major factor in ethical decision-making. Marketers using this strategy may, therefore, act unethically on behalf of their organizations, especially because neutralization helps them to mitigate or eliminate the ethical issues involved in their decisions (Chatzidakis et al. 2007; Umphress and Bingham 2011).

The second strategy is based on the benefit provided to the patient and is accompanied by a strong search for social support. It seems particularly powerful in justifying ethically problematic behavior. Hiding the profit-making purpose of their activity, these marketers stress the well-being of patients as a transcendental value. This is a double-edged sword; thus, it is recognized that health care offerings carry risks, but these risks are said to be taken in the name of a noble mission. This strategy makes it possible to maintain a self-image (Travis and Aronson 2015) that accords with 
the care mission that the respondents have assigned themselves, or even to improve it. However, it reveals the ambivalence involved in taking recourse to the patient benefit argument, which, instead of preventing abuses, can be used to justify them. It also shows the paradoxical posture of marketers who present the purpose of their work (and their professional identity) in a way that is very similar to that of healthcare professionals, who highlight their humanitarian attributes (altruism, service to the community). This leads to risky situations in which marketers exceed their role; this needs to be investigated in greater detail. Marketers using this strategy can, therefore, cross ethical boundaries in the name of the noble cause pursued by their organization. This strategy makes it possible to close the gap between the pro-business behavior of the marketers and the importance given to the well-being of the patient (Odou and Bonin 2014).

The third strategy for reducing dissonance involves avoiding the problematic behavior, by changing their job/mission within the company, resigning from the company or even leaving the pharmaceutical sector. Marketers perceive that they are constrained to perform an act incongruent with their values on behalf of their organization. In the literature, when individuals feel that their actions are highly constrained, they are less likely to experience moral dissonance, because it is easier for them to shift responsibility onto their organization (Ashforth and Anand 2003; Tsang 2002). Yet in our study, respondents report strong psychological discomfort. In this specific context, being constrained may even increase moral dissonance, since respondents may feel they are trapped. In this strategy, denying responsibility proves to be insufficient to reduce the strong moral dissonance experienced. Faced with this situation, the available alternatives are all very costly from a psychological point of view (Tsang 2002). Changing attitude would mean renouncing one's values and changing behavior would mean disobeying one's superiors or violating the rules established by the organization. The avoidance solution appears to be the least difficult for these respondents. It is nevertheless costly: the decision to resign from the company or even leave the 
sector has serious consequences. These results are in line with Festinger's (1957) suggestion that when the strategies adopted are not effective in reducing dissonance, this can lead individuals to avoidance of situations potentially generating dissonance in order to escape from the psychological discomfort. The types of employee reactions to unethical pressure exerted by the organization (e.g. whistleblowing, voluntary turnover) could be examined, as suggested by Ashforth and Anand (2003), including the degree of organizational constraint and its nature (financial incentives, obedience to authority, etc.).

Our results therefore show that in the face of strong moral dissonance, neutralizations are effective in some cases (strategy 2), while they are insufficient in other cases in which respondents need to resort to avoidance mechanisms (strategy 3). Apart from the difference in perception of the constraint (absent in strategy 2 and present in strategy 3), other factors may come into play. Further research could be carried out including individual factors such as the stage of moral development (Kohlberg 1969; Umphress and Bingham 2011), self-esteem (Holland et al. 2002; Lowell 2011), and self-affirmation (Lowell 2011), as well as traditional factors pertaining to ethical decisionmaking, such as gender, age, professional experience and religious belief (Loe et al. 2000; O'Fallon and Butterfield 2005). We can also take into account situational variables, such as employability, family commitment, compensation and sectorial specificities, because these might deter employees from resigning (Doblhofer et al. 2019).

Besides, our results on moral dissonance reduction strategies show a combination of different modes: self-justification/neutralization, social support or avoidance of problematic situations. This is a far more nuanced way to look at these strategies since till then, research on moral dissonance (Holland 2002; Lowell 2011) had highlighted the fact that the main mode of reduction adopted was self-justification. Particularly, one point of importance is the specific forms that social support 
takes within an organization based on internal processes. These are useful because they allow the marketer to consolidate his/her positions and to converge different opinions towards collective decision-making. These two elements are likely to resolve dissonance in accordance with Festinger's theory. However, respondents sometimes need to place themselves outside the organizational framework by seeking external support. This contributes to the desire to forge an intimate conviction, a doubt hanging over the objectivity of the arguments used internally. This last remark is in line with the idea developed by social psychology researchers that social support is a confirmation bias (Travis et Aronson, 2015), e.g., a process that consists of comforting oneself. The dynamics of social support within organizations are therefore to be studied in greater depth, as well as their motivations.

Finally, our results allow us to bring more nuances to the content of the self-justifications evoked, due not only to the methodology but also to crossing moral dissonance with neutralization which creates mutual enrichment (Hinojosa et al., 2017). More precisely, our findings question the nature of justifications which are supposed to be mainly external in the face of moral dissonance, according to Holland (2001) and Lowell (2011) (shifting responsibility, blaming victims). In our study, we certainly observe displacement of responsibility, or a dilution of the latter, but no denial of victims. This could be related to the sector being studied. It seems difficult to blame patients who are sick. In addition, unlike what Lowell proposes, marketers also use internal justifications such as denial of injury. More broadly, we enrich the arsenal of strategies adopted to deal with moral dissonance, notably by highlighting the importance of the appeal to higher loyalty. In addition, we note that the content of the justifications is influenced by the sector, as suggested by previous work (Sachet-Milliat et al. 2017). Specifically, it is influenced by the way respondents articulate the dual economic/health mission of the pharmaceutical sector. In strategy 1, the two missions are presented as non-contradictory. In strategy 2 , the health mission is emphasized to the 
point of omitting the economic dimension. Finally, in strategy 3, the economic dimension is perceived as dominant over the health mission.

Several possible practical recommendations can be considered, despite their various limitations. At the company level, it seems important to make general management aware of the existence of moral dissonance and the psychological distress stemming from it. Incongruence between the organization's values and those of employees' has been shown to have negative consequences in terms of job satisfaction, well-being, performance, work commitment and turnover intentions (Amos and Weathington 2008; Bao et al. 2013; Kristof-Brown et al. 2005; Siegall and McDonald 2004). As our findings have shown, this is the case in the pharmaceutical industry. The distress generated by moral dissonance is all the stronger as it concerns a noble cause (health) to which the respondents are generally very attached. They are thus trapped in a distressing situation. Taking account of the fact that certain categories of employees are particularly exposed to moral dissonance could help career management within organizations. One idea would be to allow those in sensitive professions in terms of ethical issues to move to other jobs within the company. The main challenge is to avoid employee turnover and to maintain work commitment.

It also seems useful to raise awareness about the different strategies adopted by marketers to reduce dissonance in the face of ethically problematic situations. These strategies can promote unethical employee behaviors and therefore generate reputational risks for the company. Several levers could be used to manage these risks. First of all, it is important to train marketers by promoting a reflective approach on the mechanisms for resolving inconsistency and identifying neutralizing discourses. It also seems necessary to develop more collegiality in decision-making during the consultation phases, in particular by opening discussions to external health professionals who offer a different vision of organizational discourses. 
Nevertheless, there is the question of the willingness of general managers to prevent unethical behavior by marketers when they are generally committed to their organization (Umphress and Bingham 2011). To enable employees in the pharmaceutical sector to better reconcile the tension between the health-care mission and profit-seeking, the public benefit corporation could offer solutions. This involves including a societal purpose in the articles of incorporation in order to impose, in addition to the financial assessment of the results, an evaluation on the company's societal role (Levillain 2017). Externally, the ethical dimension of different marketing practices should be more systematically integrated into marketing training, especially in specialized health marketing courses.

Finally, issues of professional identity and ethics could be addressed (Brinkmann 2002). Marketers in the pharmaceutical industries are in close contact with health professionals, doctors and pharmacists. Their profession has a common societal function aimed at consumer well-being. Nevertheless, marketers are generally less scientifically equipped than health professionals to deal with "patient" issues and their profession is less regulated than that of health workers, who are subject to strict ethics. This discrepancy gives rise to a need for medical training for marketers so that they are able to better able discuss health issues with their interlocutors. In addition, the question also arises of improving codes of ethics at the sectoral level, which so far have proved to be ineffective (Verschoor 2011).

\section{Conclusion, limits and future research avenues}

This research examines how marketers identify and experience the fundamental ethical conflict that drives them to make economically motivated decisions at the expense of the health mission in 
which they are expected to participate. Based on the narratives of executives working in companies and not on fictitious scenarios, it contributes to the understanding of the moral dissonance concept and the strategies adopted to deal with these situations of moral dissonance, including the justifications invoked.

One main aspect of our study -the modes of moral dissonance reduction- has some limitations. Despite the precautions taken to approach the field, it is difficult to know whether respondents were frank when answering our questions. The absence of ethical conflicts noticeable for some respondents may be the result of a strategy to reduce moral dissonance or the manifestation of a bias related to the sensitivity of the research and/or the methodology used.

In addition, while our results highlighted three strategies, it was not possible for us to take into account respondent's individual factors, such as stage of moral development, personality, value system, etc., that could explain these differences in strategies. This opens up promising avenues of research.

The justifications mobilized by respondents appear to be based on different substantive arguments depending on the sectors of activity in which they are observed (Sachet-Milliat et al. 2017). We note that the care mission assigned to the pharmaceutical industry has a major influence on the neutralization discourses of marketers working in this sector. It seems that we have with the pharmaceutical industry, the case of unethical behavior which can sometimes be paradoxically justified by the moral nature of the sector. This hypothesis would have to be confirmed by further research. It would be interesting to study this phenomenon in areas where altruism, benevolence and virtue are central values such as in charitable organizations. 


\section{Appendix 1: Interview guide}

I am conducting a scientific study on situations of ethical problems experienced by marketing professionals. In the interview, I would like you to tell me about problems or cases of conscience that you have encountered in the course of your duties /decision-making in marketing in France. What you say will remain strictly confidential. Neither your name nor the name of your company will be mentioned. This data will be used only in the context of publications in academic journals.

\section{Could you briefly introduce yourself and say something about your job and career?}

2. In your professional career (and specifically your role in marketing) have you ever been faced by a situation that has bothered your conscience? If this has happened on a number of occasions, focus on one or two that that most affected you. Can you tell me about it?

Follow-up on the description of the problem mentioned:

- Description of the problem

- Description of the organizational context (hierarchy, corporate culture, codes of ethics, legal department, etc.)

- Description of the external context (regulatory, economic, customer, sector, etc.)

- Protagonists: people or groups involved in the problem (legal/regulatory, general management, other departments, etc.)

- Focus on relations with the legal/regulatory department: description of the validation process, cases of projects rejected by the legal department

Follow-up on cases of conscience and how they were resolved:

- What did you do in this situation? And why?

- What decision(s) did you make?

- Can you explain why you chose to do this?

- Have you solicited other people (in the professional context? in the personal context?)

Follow-up on other situations giving rise to cases of conscience:

- Were there any operations where you thought you were going to cross a line?

- Were there any other decisions where you felt you were in an awkward position?

- Do you have examples of operations carried out by the competition that could have troubled your conscience if you had had to do them yourself?

\section{And the fact of working in this sector, how was that initially?}

Follow-up:

- Did you experience agreeing to take this job as a problem?

- Why did you agree to it?

4. Finally, are there any sectors in which you would not work? For what reasons? 
Appendix 2: Adaptation of the field to its sensitive nature (From author, 2009)

\begin{tabular}{|c|c|}
\hline $\begin{array}{l}\text { Problems induced by the } \\
\text { sensitive field }\end{array}$ & Resolution \\
\hline \multicolumn{2}{|l|}{ Access to the field } \\
\hline $\begin{array}{lll}\text { Gain the } & \text { trust } & \text { of } \\
\text { interviewees to agree } & \text { to } \\
\text { participate } & & \end{array}$ & $\begin{array}{l}\text { Use the method from one person to another but with several } \\
\text { starting points to avoid excessive homogeneity of the } \\
\text { characteristics of the sample. Two different channels were } \\
\text { used, initiated by the professional experience of one of the } \\
\text { researchers. }\end{array}$ \\
\hline Obtain informed consent & $\begin{array}{l}\text { Communicate the instructions to the interviewee before the } \\
\text { interview. }\end{array}$ \\
\hline \multicolumn{2}{|l|}{ Data collection } \\
\hline $\begin{array}{l}\text { Access the meaning that the } \\
\text { interviewees give to their } \\
\text { actions }\end{array}$ & Conduct a semi-directive interview. \\
\hline $\begin{array}{l}\text { Reduce the potential stress } \\
\text { induced by the interviewee's } \\
\text { participation in the research }\end{array}$ & $\begin{array}{l}\text { Protect confidentiality by guaranteeing the anonymity of } \\
\text { respondents and destruction of recordings after transcribing } \\
\text { interviews. }\end{array}$ \\
\hline $\begin{array}{l}\text { Create a climate of trust } \\
\text { favorable to confidences }\end{array}$ & $\begin{array}{l}\text { Adopt an empathetic listening and an attitude of benevolent } \\
\text { neutrality. } \\
\text { Choose a neutral place (avoid the professional context). } \\
\text { Proceed remotely (telephone). }\end{array}$ \\
\hline $\begin{array}{l}\text { Do not focus too explicitly } \\
\text { on the research subject }\end{array}$ & $\begin{array}{l}\text { Start with the career story. } \\
\text { Ask the broad question of the ethical problems/cases of } \\
\text { conscience encountered in the course of their activity. } \\
\text { Follow-up in the form of questions based on the interviewee's } \\
\text { speech (try not to introduce new topics not covered). }\end{array}$ \\
\hline
\end{tabular}




\section{Appendix 3: Description of the sample}

\begin{tabular}{|c|c|c|c|c|c|}
\hline Id. & $\mathrm{S}$ & $\begin{array}{l}\text { Age (in } \\
\text { years) }\end{array}$ & Function(s) & Type(s) of offer & $\begin{array}{l}\text { Type of structure (number of years), } \\
\text { number of pharmaceutical lab, sector exit } \\
\text { (yes/no) }\end{array}$ \\
\hline 1 & $\mathrm{H}$ & $40-45$ & $\begin{array}{l}\text { Marketing } \\
\text { General manager }\end{array}$ & $\begin{array}{l}\text { Prescribed medicines } \\
\text { Nicotine substitutes } \\
\text { Health nutrition } \\
\text { Infectious diseases }\end{array}$ & $\begin{array}{l}\text { Pharmaceutical labs (17), } \\
3 \text {, no }\end{array}$ \\
\hline 2 & $\mathrm{H}$ & $50-55$ & $\begin{array}{l}\text { Sales } \\
\text { General manager }\end{array}$ & $\begin{array}{l}\text { Agri-food industry } \\
\text { Prescribed infant milks } \\
\text { Prescribed medicines } \\
\text { Prescribed care devices }\end{array}$ & $\begin{array}{l}\text { Non-health private companies }(25) \text {, } \\
\text { Pharmaceutical lab }(1,5) \text {, } \\
\text { Other health private company }(1,5) \text {, } \\
1 \text {, yes }\end{array}$ \\
\hline 3 & $\mathrm{H}$ & $50-55$ & $\begin{array}{l}\text { Marketing } \\
\text { General manager }\end{array}$ & $\begin{array}{l}\text { Phytosanitary products } \\
\text { Cosmetics } \\
\text { Prescribed medicines }\end{array}$ & $\begin{array}{l}\text { Non-health private companies }(7), \\
\text { Pharmaceutical labs }(18), \\
2, \text { no }\end{array}$ \\
\hline 4 & $\mathrm{~F}$ & $50-55$ & Marketing & $\begin{array}{l}\text { Agri-food industry } \\
\text { Non prescribed medicines } \\
\text { Prescribed medicines }\end{array}$ & $\begin{array}{l}\text { Non-health private companies (4), } \\
\text { Pharmaceutical labs }(20), \\
3 \text {, no }\end{array}$ \\
\hline 5 & $\mathrm{~F}$ & $45-50$ & Marketing & $\begin{array}{l}\text { Fast moving consumer goods } \\
\text { Non prescribed medicines } \\
\text { Teaching }\end{array}$ & $\begin{array}{l}\text { Non-health private companies (16), } \\
\text { Pharmaceutical labs }(5), \\
1 \text {, yes }\end{array}$ \\
\hline 6 & $\mathrm{~F}$ & $35-40$ & Marketing & $\begin{array}{l}\text { Cosmetics, non prescribed and } \\
\text { prescribed medicines }\end{array}$ & $\begin{array}{l}\text { Pharmaceutical labs (18), } \\
3, \text { no }\end{array}$ \\
\hline 7 & $\mathrm{~F}$ & $50-55$ & $\begin{array}{l}\text { Marketing } \\
\text { Communication }\end{array}$ & Prescribed medicines & $\begin{array}{l}\text { Pharmacy (2), Pharmaceutical lab (3), } \\
\text { Communication consulting agency (3), } \\
1, \text { no }\end{array}$ \\
\hline 8 & $\mathrm{H}$ & $30-35$ & $\begin{array}{l}\text { R\&D } \\
\text { Marketing } \\
\text { CEO }\end{array}$ & $\begin{array}{l}\text { Regulated parapharmacy } \\
\text { products }\end{array}$ & $\begin{array}{l}\text { Pharmaceutical labs (14), } \\
\text { Consulting agency (4), } \\
2, \text { no }\end{array}$ \\
\hline 9 & $\mathrm{H}$ & $30-35$ & $\begin{array}{l}\text { Marketing } \\
\text { Sales }\end{array}$ & $\begin{array}{l}\text { Prescribed medicines } \\
\text { Prescribed care services }\end{array}$ & $\begin{array}{l}\text { Pharmaceutical lab (1), } \\
\text { Health financing structure (6), } \\
1 \text {, yes }\end{array}$ \\
\hline 10 & $\mathrm{~F}$ & $25-30$ & $\begin{array}{l}\text { Sales } \\
\text { Marketing }\end{array}$ & $\begin{array}{l}\text { Non prescribed products } \\
(\text { slimming cream }, \ldots)\end{array}$ & $\begin{array}{l}\text { Pharmaceutical labs }(4) \\
2, \text { yes }\end{array}$ \\
\hline 11 & $\mathrm{H}$ & $25-30$ & $\begin{array}{l}\text { Sales } \\
\text { Marketing }\end{array}$ & $\begin{array}{l}\text { Agri-food industry } \\
\text { Non prescribed medicines } \\
\text { Reimbursed medicines } \\
\end{array}$ & $\begin{array}{l}\text { Non-health private companies }(3) \text {, } \\
\text { Pharmaceutical lab }(2,5), \\
1, \text { no }\end{array}$ \\
\hline 12 & $\mathrm{~F}$ & $25-40$ & Marketing & $\begin{array}{l}\text { Health edition } \\
\text { Medical devices } \\
\text { Prescribed medicines }\end{array}$ & $\begin{array}{l}\text { Non-health private companies (6), } \\
\text { Optics (6), } \\
\text { Pharmaceutical lab (2), } \\
1 \text {, no }\end{array}$ \\
\hline 13 & $\mathrm{~F}$ & $25-30$ & $\begin{array}{l}\text { Sales } \\
\text { Marketing }\end{array}$ & $\begin{array}{l}\text { Prescribed medicines } \\
\text { Non prescribed medicines }\end{array}$ & $\begin{array}{l}\text { Pharmaceutical labs (5), } \\
1 \text {, no }\end{array}$ \\
\hline 14 & $\mathrm{~F}$ & $45-50$ & $\begin{array}{l}\text { Marketing } \\
\text { HR }\end{array}$ & Prescribed medicines & $\begin{array}{l}\text { Pharmaceutical labs (25), } \\
2, \text { no }\end{array}$ \\
\hline 15 & $\mathrm{~F}$ & $55-60$ & $\begin{array}{l}\text { Medical } \\
\text { Sales }\end{array}$ & Prescribed medicines & $\begin{array}{l}\text { Pharmaceutical labs (30), } \\
6, \text { yes }\end{array}$ \\
\hline 16 & $\mathrm{~F}$ & $25-30$ & Marketing & Prescribed medicines & $\begin{array}{l}\text { Pharmaceutical labs (3), } \\
1, \text { no }\end{array}$ \\
\hline 17 & $\mathrm{H}$ & $45-50$ & $\begin{array}{l}\text { Marketing } \\
\text { Sales } \\
\text { General manager }\end{array}$ & All types of medicines & $\begin{array}{l}\text { Non-health private companies (7), } \\
\text { Pharmaceutical labs (18), } \\
2, \text { no }\end{array}$ \\
\hline 18 & $\mathrm{~F}$ & $40-45$ & $\begin{array}{l}\text { Medical } \\
\text { Marketing }\end{array}$ & Prescribed devices & $\begin{array}{l}\text { Consulting agency (4), } \\
\text { Pharmaceutical labs (7), } \\
2 \text {, no }\end{array}$ \\
\hline
\end{tabular}




\section{Appendix 4: Elements of data collection by respondent}

\begin{tabular}{|c|c|c|c|}
\hline Id. & $\begin{array}{c}\text { Preliminary } \\
\text { contacts }\end{array}$ & $\begin{array}{l}\text { Duration of the } \\
\text { interview } \\
\text { (mn) }\end{array}$ & $\begin{array}{c}\text { Number of } \\
\text { words in the } \\
\text { interview }\end{array}$ \\
\hline 1 & 1 & 64 & 9193 \\
\hline 2 & 2 & 50 & 7539 \\
\hline 3 & 1 & 50 & 7476 \\
\hline 4 & 1 & 52 & 6560 \\
\hline $5^{*}$ & - & - & 2168 \\
\hline 6 & 2 & 58 & 8057 \\
\hline 7 & 1 & 38 & 7318 \\
\hline 8 & 1 & 56 & 8789 \\
\hline 9 & 1 & 38 & 3014 \\
\hline 10 & 1 & 53 & 6269 \\
\hline 11 & 2 & 55 & 7022 \\
\hline 12 & 2 & 43 & 7014 \\
\hline 13 & 1 & 53 & 8181 \\
\hline 14 & 1 & 53 & 9191 \\
\hline 15 & 2 & 56 & 6619 \\
\hline 16 & 1 & 46 & 5205 \\
\hline 17 & 1 & 47 & 6682 \\
\hline 18 & 1 & 60 & 9823 \\
\hline Total & & 872 & 126120 \\
\hline
\end{tabular}

* Written introspection conducted by one of the researchers who worked in the pharmaceutical industry. 
Appendix 5: Coding grid for moral dissonance reduction strategies

\begin{tabular}{|c|c|c|c|}
\hline $\begin{array}{l}\text { Type of reduction's } \\
\text { mode }\end{array}$ & Definition & Theory & Reference \\
\hline $\begin{array}{l}\text { 1. Changing } \\
\text { problematic } \\
\text { behaviour }^{1}\end{array}$ & $\begin{array}{l}\text { Changing the behaviour } \\
\text { that is dissonant with } \\
\text { attitude (counter attitudinal } \\
\text { behavior) }\end{array}$ & $\begin{array}{l}\text { Cognitive } \\
\text { dissonance (social } \\
\text { psychology) }\end{array}$ & Festinger (1957) \\
\hline \multicolumn{4}{|c|}{ 2. Cognitive rationalizations } \\
\hline $\begin{array}{l}\text { Changing attitude } \\
\text { towards behaviour }^{2}\end{array}$ & $\begin{array}{l}\text { Modifying one's attitude } \\
\text { to make it more consistent } \\
\text { with the problematic } \\
\text { behavior }\end{array}$ & \multirow[t]{2}{*}{$\begin{array}{l}\text { Cognitive } \\
\text { dissonance (social } \\
\text { psychology) }\end{array}$} & \multirow[t]{2}{*}{ Festinger (1957) } \\
\hline Trivialization $^{3}$ & $\begin{array}{l}\text { Minimizing the } \\
\text { importance of the } \\
\text { cognitive elements in } \\
\text { conflicts }\end{array}$ & & \\
\hline \multirow[t]{2}{*}{ Adding new cognitions } & Self-justifications & $\begin{array}{l}\text { Moral dissonance } \\
\text { (social } \\
\text { psychology) }\end{array}$ & $\begin{array}{l}\text { Kelman (1974), } \\
\text { Holland et al. } \\
\text { (2002), Lowell } \\
(2011)\end{array}$ \\
\hline & $\begin{array}{l}\text { Neutralizations ( } 5 \\
\text { techniques): } \\
\text { Resorting to justification } \\
\text { mechanism when } \\
\text { someone's behavior } \\
\text { deviates from the } \\
\text { dominant social norms to } \\
\text { which he or she is attached }\end{array}$ & $\begin{array}{l}\text { Neutralization } \\
\text { (Sociology of } \\
\text { deviance) }\end{array}$ & $\begin{array}{l}\text { Sykes and Matza } \\
\text { (1957) }\end{array}$ \\
\hline 3. Social support & $\begin{array}{l}\text { Seeking social support } \\
\text { from individuals who } \\
\text { share the same point of } \\
\text { view in order to reinforce } \\
\text { attitudes, opinions or } \\
\text { decisions }\end{array}$ & $\begin{array}{l}\text { Cognitive } \\
\text { dissonance (social } \\
\text { psychology) }\end{array}$ & Festinger (1957) \\
\hline$\frac{\text { 4. Avoidance of }}{\text { dissonance }}$ & $\begin{array}{l}\text { Refraining from making } \\
\text { decisions in contexts } \\
\text { similar to these leading to } \\
\text { dissonance experience }\end{array}$ & $\begin{array}{l}\text { Cognitive } \\
\text { dissonance (social } \\
\text { psychology) }\end{array}$ & Festinger (1957) \\
\hline
\end{tabular}

\footnotetext{
${ }^{1}$ We underlined the concepts used for our analytical coding of the strategies used by marketers

${ }^{2}$ Changing attitude towards behaviour has not been used for coding because it is not applicable in the case of moral dissonance (see literature review)

${ }^{3}$ Trivialization has not been used for coding since it overlaps the concept of denial of injury (see discussion)
} 
Appendix 6. Moral intensity coding grid from Jones (1991)

\begin{tabular}{|c|c|c|c|}
\hline $\mathbf{0}$ & 1 & 2 & 3 \\
\hline \multicolumn{4}{|c|}{ Magnitude of consequences } \\
\hline $\begin{array}{l}\text { No consequence for } \\
\text { individuals } \\
\text { (n.r.) }\end{array}$ & $\begin{array}{l}\text { Non dangerous for } \\
\text { health for } \\
\text { individuals } \\
\text { i.e. Pharmacy } \\
\text { discounts }\end{array}$ & $\begin{array}{l}\text { Significant health } \\
\text { consequences for } \\
\text { individuals } \\
\text { i.e. Mild side effects, } \\
\text { treatment's } \\
\text { compliance } \\
\text { problems }\end{array}$ & $\begin{array}{l}\text { Serious } \\
\text { consequences on } \\
\text { health for individuals } \\
\text { i.e. Serious side } \\
\text { effects (cancer or } \\
\text { even lethal) }\end{array}$ \\
\hline \multicolumn{4}{|l|}{ Probability of effect } \\
\hline No risk & $\begin{array}{l}\text { Hypothetical risk } \\
\text { i.e. Small risks of } \\
\text { misusage }\end{array}$ & $\begin{array}{l}\text { Documented risk } \\
\text { i.e. Known risks on } \\
\text { some molecules }\end{array}$ & $\begin{array}{l}\text { Demonstrated risk } \\
\text { i.e. Existing damages }\end{array}$ \\
\hline \multicolumn{4}{|c|}{ Temporal immediacy } \\
\hline No time schedule & $\begin{array}{l}\text { Long term } \\
\text { i.e. More than } 20 \\
\text { years }\end{array}$ & $\begin{array}{l}\text { Medium term } \\
\text { i.e. Between } 20 \text { and } \\
5\end{array}$ & $\begin{array}{l}\text { Short term } \\
\text { i.e. Within } 5 \text { years }\end{array}$ \\
\hline \multicolumn{4}{|l|}{ Proximity } \\
\hline $\begin{array}{l}\text { No contact with } \\
\text { patient }\end{array}$ & $\begin{array}{l}\text { Low } \\
\text { i.e. Indirect patient } \\
\text { contact (via } \\
\text { pharmacists or } \\
\text { health practioners) }\end{array}$ & $\begin{array}{l}\text { Medium } \\
\text { i.e. Contact with } \\
\text { patient's problem }\end{array}$ & $\begin{array}{l}\text { High } \\
\text { i.e. Direct contact } \\
\text { with patient, } \\
\text { identification to } \\
\text { patient }\end{array}$ \\
\hline \multicolumn{4}{|l|}{ Social consensus } \\
\hline No social issue & $\begin{array}{l}\text { Minor social issue } \\
\text { i.e. Illegal sales } \\
\text { discounts to } \\
\text { pharmacists }\end{array}$ & $\begin{array}{l}\text { Ethical problem not } \\
\text { endangering health } \\
\text { but challenging } \\
\text { heath profession's } \\
\text { integrity } \\
\text { i.e. Gifts, actions } \\
\text { toward health } \\
\text { professionals }\end{array}$ & $\begin{array}{l}\text { Problem directly } \\
\text { endangering the } \\
\text { health of different } \\
\text { audiences } \\
\text { i.e. Deliberate } \\
\text { actions towards } \\
\text { fragile patients } \\
\text { (children, pregnant } \\
\text { women, security } \\
\text { rules violations, sick } \\
\text { people) }\end{array}$ \\
\hline
\end{tabular}


Appendix 7: Summary table of results

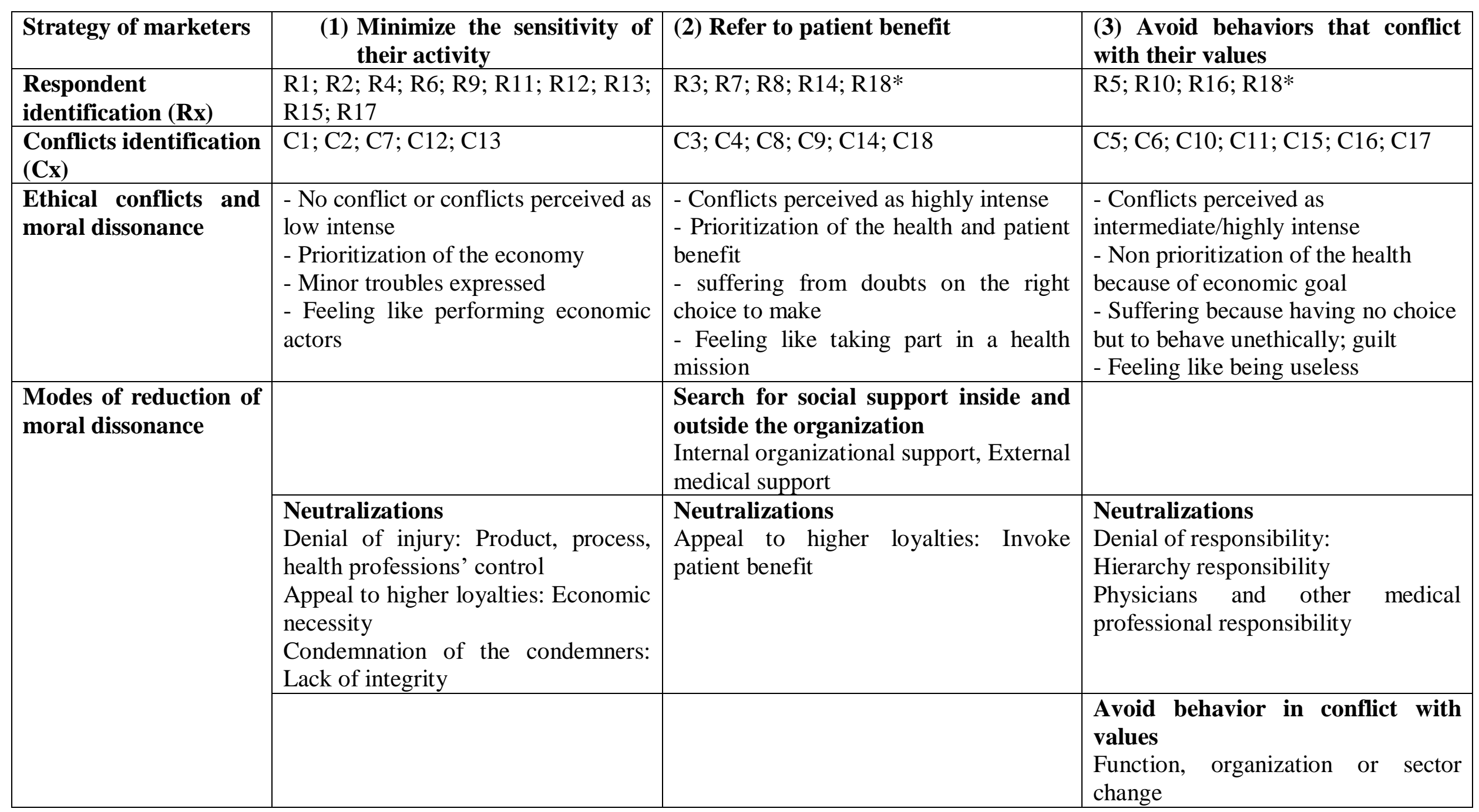

* This interviewee appears in two different groups because she relates two different cases

experienced in different structures and at different times in her professional life. 


\section{References}

Amos, E. A. and Weathington, B. L. (2008). An analysis of the relation between employeeorganization value congruence and employee attitudes. The Journal of Psychology 142(6), 615632.

Ashforth, B. E. and Anand, V. (2003). The normalization of corruption in organizations.

Research in Organizational Behavior 25, 1-52.

Ashforth, B. E., Kreiner, G. E., Clark, M. A. and Fugate, M. (2007). Normalizing dirty work: Managerial tactics for countering occupational taint. Academy of Management Journal 50(1), 149174.

Bandura A., Barbaranelli C., Caprara G. V., et al. (1996) Mechanisms of moral disengagement in the exercise of moral agency. Journal of Personality and Social Psychology 71(2): 364-374.

Bao, Y., Vedina, R., Moodie, S. and Dolan, S. (2013). The relationship between value incongruence and individual and organizational well-being outcomes: an exploratory study among Catalan nurses. Journal of Advanced Nursing 69(3), 631-641.

Barnet, T. (2001). Dimensions of moral intensity and ethical decision making: An empirical study. Journal of Applied Social Psychology. 31(5), 1038-1057.

Bazerman, M. H. and Banaji, M. R. (2004). The social psychology of ordinary ethical failures. Social Justice Research 17(2), 111-115.

Bazerman, M. H. and Gino, F. (2012). Behavioral ethics: Toward a deeper understanding of moral judgment and dishonesty. Annual Review of Law and Social Science 8, 85-104.

Chatzidakis, A., Hibbert, S. and Smith, A. (2007). Why people don't cake their concerns about fair trade to the supermarket: The role of neutralisation. Journal of Business Ethics 74(1), 89-100. 
Cohn, A., Fehr, E. and Maréchal, M. A. (2014). Business culture and dishonesty in the banking industry. Nature 516(7529), 86-97.

Cohn, J. (2016). The drug price controversy nobody notices. The Milbank Quarterly 94(2), 260263.

Cooper, J. and Fazio, R. H. (1984). A new look at dissonance theory. In Advances in Experimental Social Psychology 17, 229-266.

Crié, D. and Chebat, J.-C. (2013). Health marketing: Toward an integrative perspective. Journal of Business Research 66(1), 123-126.

Cromwell, P. and Birzer, M. L. (2012). The curious case of George: A case study of a career criminal. Criminal Justice Review 37(4), 512-526.

Dion, M. (2012). Confits, dilemmes et crises éthiques sont-ils synonymes ? [im]pertinences (2), 73-85.

Divard, R. (2013). Comprendre les comportements non éthiques du consommateur : les apports de la théorie de la neutralisation. Management \& Avenir 60(2), 53-73.

Doblhofer, D. S., Hauser, A., Kuonath, A., Haas, K., Agthe, M. and Frey, D. (2019). Make the best out of the bad: Coping with value incongruence through displaying facades of conformity, positive reframing, and self-disclosure. European Journal of Work and Organizational Psychology 28(5), $572-593$.

Edwards, J. R. and Cable, D. M. (2009). The value of value congruence. Journal of Applied Psychology 94(3), 654-677.

Festinger, L. (1957). A theory of cognitive dissonance. Stanford University Press.

Festinger, L. (1999). Reflections on cognitive dissonance: 30 years later. Cognitive dissonance: Progress on a pivotal theory in social psychology, 381-385.

Fournier, P., Muller, S. and Lomba, C. (2014). Les travailleurs du médicament : L'industrie pharmaceutique sous observation. Eres. 
Gosling, P., Denizeau, M. and Oberlé, D. (2006). Denial of responsibility: A new mode of dissonance reduction. Journal of Personality and Social Psychology, 90(5), 722.

Gunia, B. C., Wang, L., Huang, L. I., Wang, J., and Murnighan, J. K. (2012). Contemplation and conversation: Subtle influences on moral decision making. Academy of Management Journal, $55(1), 13-33$.

Heath, J. (2008). Business ethics and moral motivation: A criminological perspective. Journal of Business Ethics 83(4), 595-614.

Hinojosa, A. S., Gardner, W. L., Walker, H. J., Cogliser, C. and Gullifor, D. (2017). A review of cognitive dissonance theory in management research: Opportunities for further development. Journal of Management 43(1), 170-199.

Holland, R. W., Meertens, R. M. and Van Vugt, M. (2002). Dissonance on the road: Self-esteem as a moderator of internal and external self-justification strategies. Personality and Social Psychology Bulletin 28(12), 1713-1724.

Huebner, J. M. (2014). Moral psychology and the intuition that pharmaceutical companies have a 'special' obligation to society. Journal of Business Ethics 122(3), 501-510.

Jones, T. M. (1991). Ethical decision making by individuals in organizations: An issue-contingent model. Academy of Management Review 16(2), 366-395.

Kammeyer-Mueller, J. D., Simon, L. S. and Rich, B. L. (2012). The psychic cost of doing wrong: Ethical conflict, divestiture socialization, and emotional exhaustion. Journal of Management 38(3), 784-808.

Katamba, D., Marvin Nkiko, C. and Ademson, C. (2016). Managing stakeholders' influence on embracing business code of conduct and ethics in a local pharmaceutical company: Case of Kampala Pharmaceutical Industries (KPI). Review of International Business and Strategy 26(2), 261-290. 
Kelman, H. C. and Baron, R. M. (1974). Moral and hedonic dissonance: A functional analysis of the relationship between discrepant action and attitude change. In S. Himmelfarb \& A.H. Eagly (Eds), Readings in attitude change (pp. 558-575). New York: John Wiley.

Kohlberg, L. (1969). Stage and sequence: The cognitive-developmental approach to socialization. In D.A. Gosling (Ed.), Handbook of Socialization Theory and Research. Rand McNally, 347-380. Konovsky, M. A. and Jaster, F. (1989). "Blaming the victim" and other ways businessmen and women account for questionable behavior. Journal of Business Ethics 8(5), 391-398.

Kristof-Brown, A. L., Zimmerman, R. D. and Johnson, E. C. (2005). Consequences of individuals' fit at work: a meta-analysis of person-job, person-organization, person-group, and personsupervisor fit. Personnel psychology 58(2), 281-342.

Loe, T. W., Ferrell, L. and Mansfield, P. (2000). A review of empirical studies assessing ethical decision making in business. Journal of Business Ethics 25(3), 185-204.

Lowell, J. (2011). Managers and moral dissonance: Self-justification as a big threat to ethical management? Journal of Business Ethics 105(1), 17-25.

McGregor, S. L. (2008). Conceptualizing immoral and unethical consumption using neutralization theory. Family and Consumer Sciences Research Journal 36(3), 261-276.

Maitland, I. (2002). Priceless goods: How should life-saving drugs be priced? Business Ethics Quarterly 12(4), 451-480.

Maruna, S. and Copes, H. (2005). What have we learned from five decades of neutralization research? Crime and Justice 32, 221-320.

McGrath, A. (2017). Dealing with dissonance: A review of cognitive dissonance reduction. Social and Personality Psychology Compass 11(12), 1-17.

Messick, D. M. and Tenbrunsel, A. E. (1996). Codes of conduct: Behavioral research into business ethics. Russell Sage Foundation. 
Minor, W. W. (1981). Techniques of neutralization: A reconceptualization and empirical examination. Journal of Research in Crime and Delinquency 18(2), 295-318.

Nussbaum, A.S.K. (2009). Ethical corporate social responsibility (CSR) and the pharmaceutical industry: A happy couple? Journal of Medical Marketing 9(1), 67-76.

O'Fallon, M. J., and Butterfield, K. D. (2005). A review of the empirical ethical decision-making literature: 1996-2003. Journal of Business Ethics 59(4), 375-413.

Odou, P. and Bonnin, G. (2014). Consumers' neutralization strategies to counter normative pressure: the case of illegal downloading. Recherche et Applications en Marketing (English edition) 29(1), 103-121.

Ravelli, Q. (2015). La Stratégie de la bactérie. Une enquête au cœur de l'industrie pharmaceutique. Le Seuil.

Ribeaud, D. and Eisner, M. (2010). Are moral disengagement, neutralization techniques, and selfserving cognitive distortions the same? Developing a unified scale of moral neutralization of aggression. International Journal of Conflict and Violence 4(2), 298-315.

Rokeach, M. (1968). Beliefs, attitudes and values; a theory of organization and change. Journal of Social Issues 24(1), 13-33.

Sachet-Milliat, A., Baïada-Hirèche, L. and Bourcier-Béquaert, B. (2017). The clear conscience of the controversial sector marketer: A neutralization theory approach. Recherche et Applications en Marketing (English Edition) 32(3), 28-48.

Sah, S. and Fugh-Berman, A. (2013). Physicians under the influence: social psychology and industry marketing strategies. The Journal of Law, Medicine \& Ethics 41(3), 665-672.

Serviere-Munoz, L. and Mallin, M. L. (2013). How do unethical salespeople sleep at night? The role of neutralizations in the justification of unethical sales intentions. Journal of Personal Selling \& Sales Management 33(3), 289-306. 
Shaw, B. and Whitney, P. (2016). Ethics and compliance in global pharmaceutical industry marketing and promotion: The role of the IFPMA and self-regulation. Pharmaceuticals Policy and Law 18(1-4), 199-206.

Siegall, M. and McDonald, T. (2004). Person-organization value congruence, burnout and diversion of resources. Personnel Review 33(3), 291-301.

Simon, L., Greenberg, J. and Brehm, J. (1995). Trivialization: the forgotten mode of dissonance reduction. Journal of Personality and Social Psychology 68(2), 247-260.

Sims, R. R. (1992). Linking groupthink to unethical behavior in organizations. Journal of Business Ethics 11(9), 651-662.

Steele, C. M. (1988). The psychology of self-affirmation: Sustaining the integrity of the self. In L. Berkowitz (Ed.), Advances in experimental social psychology (Vol. 21, pp. 261-302). Elsevier. Steffen, J. E., Fassler, E. A., Reardon, K. J. and Egilman, D. S. (2018). Grave fraudulence in medical device research: a narrative review of the PIN seeding study for the Pinnacle hip system. Accountability in research 25(1), 37-66.

Stremersch, S. and Van Dyck, W. (2009). Marketing of the life sciences: A new framework and research agenda for a nascent field. Journal of Marketing 73(4), 4-30.

Sykes, G. M. and Matza, D. (1957). Techniques of neutralization: A theory of delinquency. American Sociological Review 22(6), 664-670.

Tong, J., Wang, L. and Peng, K. (2015). From person-environment misfit to job burnout: Theoretical extensions. Journal of Managerial Psychology 30(2), 169-182.

Travis, C. and Aronson, E. (2015). Mistakes were made (but not by me). Mariner Books, BostonNew York.

Tsang, J.-A. (2002). Moral rationalization and the integration of situational factors and psychological processes in immoral behavior. Review of General Psychology 6(1), 25-50. 
Umphress, E. E. and Bingham, J. B. (2011). When employees do bad things for good reasons: Examining unethical pro-organizational behavior. Organization Science 22, 621-640.

Vaidis, D. and Halimi-Falkowicz, S. (2007). La théorie de la dissonance cognitive : une théorie âgée d'un demi-siècle. Revue Electronique de Psychologie Sociale 1, 9-18.

Valverde, J. (2012). Ethical challenges in the pharmaceutical industry. Pharmaceuticals, Policy and Law 14(2/4), 123-127.

Van de Pol, P. K. and De Bakker, F. G. (2010). Direct-to-consumer advertising of pharmaceuticals as a matter of corporate social responsibility? Journal of Business Ethics 94(2), 211-224.

Verschoor, C. C. (2011). Pharma ethics code isn’t working! Strategic Finance 92(8), 17-20.

Vitell, S. J. and Grove, S. J. (1987). Marketing ethics and the techniques of neutralization. Journal of Business Ethics 6(6), 433-438.

Voisin, D. and Fointiat, V. (2013). Reduction in cognitive dissonance according to normative standards in the induced compliance paradigm. Social Psychology 44, 191-195.

Voisin, D., Rubens, L., N'gbala, A. and Gosling, P. (2013). Le choix du mode de réduction. In V. Fointiat, F. Girandola \& P.Gosling (Eds.), La dissonance cognitive (pp. 87-118). Armand Colin. 


\section{Notes}

${ }^{1}$ Center for Disease Control and Prevention, cited by Le Monde, January 31rst, 2020.

${ }^{2}$ Most reduction modes are already present in Festinger's initial work (1957) and have been supplemented by subsequent work (see Hinojosa et al. 2017; McGrath 2017; Vaidis and Halimi-Falkowicz 2007; Voisin et al. 2013 for a review of the existing work).

${ }^{3}$ The phenomenon of justification has given rise to numerous studies drawing on similar concepts: moral rationalization, moral justification, self-justification...

${ }^{4}$ Although they don't refer to the neutralization theory, the moral disengagement mechanisms highlighted by Bandura (1990) are surprisingly close to the neutralization techniques identified by Sykes and Matza in 1957 (Ribeaud and Eisner 2010).

${ }^{5}$ Survey from TNS Sofres in 2018.

${ }^{6}$ Laboratory in which a major health scandal (Mediator) took place in France.

7 The French national drug safety agency.

${ }^{8}$ Marketing authorization for drugs given by the health authorities in France (Autorisation de Mise sur le Marché). 